\title{
A COMPREHENSIVE SURVEY ON FORMAL CONCEPT ANALYSIS, ITS RESEARCH TRENDS AND APPLICATIONS
}

\author{
Prem KumAr SINGH $^{a}$, CherukURi ASWANi KUMAR ${ }^{b, *}$, AbDUllah GANI $^{a}$ \\ ${ }^{a}$ Centre for Mobile Cloud Computing Research, Faculty of Computer Science and Information Technology \\ University of Malaya, Kuala Lumpur 50603, Malaysia \\ e-mail: premsingh.csjmegmail.com \\ ${ }^{b}$ School of Information Technology and Engineering \\ VIT University, Vellore 632014, India \\ e-mail: cherukuri@acm.org
}

\begin{abstract}
In recent years, FCA has received significant attention from research communities of various fields. Further, the theory of FCA is being extended into different frontiers and augmented with other knowledge representation frameworks. In this backdrop, this paper aims to provide an understanding of the necessary mathematical background for each extension of FCA like FCA with granular computing, a fuzzy setting, interval-valued, possibility theory, triadic, factor concepts and handling incomplete data. Subsequently, the paper illustrates emerging trends for each extension with applications. To this end, we summarize more than 350 recent (published after 2011) research papers indexed in Google Scholar, IEEE Xplore, ScienceDirect, Scopus, SpringerLink, and a few authoritative fundamental papers.
\end{abstract}

Keywords: concept lattice, formal concept analysis, formal concept, formal context, Galois connection.

\section{Introduction}

Formal concept analysis (FCA) is a mathematical framework based on lattice theory (Wille, 1982). FCA starts data analysis from a given incidence matrix in which each row corresponds to objects, each column corresponds to attributes, and the matrix field value denotes the relationship between them. One of the major outputs of this model is the concept lattice, reflecting generalization and specialization between the derived formal concepts from the incidence matrix (Davey and Priestley, 2002). Formal concepts are a basic unit of thought and play-major role in knowledge processing tasks containing distinct extents (sets of objects) and intents (corresponding common attributes) (Ganter and Wille, 1999). To handle the uncertainty and vagueness in data, FCA has been successfully extended with a fuzzy setting, an interval-valued fuzzy setting, possibility theory, a rough setting and triadic concept analysis. These extensions have independent background mathematics, algorithms, and outputs. Several algorithms

* Corresponding author are available in the literature on FCA (Doerfel et al., 2012; Poelmans et al., 2014), its notions (Kuznetsov and Obiedkov, 2002; Poelmans et al., 2013b), theoretical analysis (Aswani Kumar and Singh, 2014; Sarmah et al., 2015), algorithms (Dias and Vieira, 2015; Kuznetsov and Obiedkov, 2002; Kuznetsov and Poelmans, 2013) and applications (Poelmans et al., 2013b; Yan et al., 2015). The current paper is unique and different from the above cited works mainly due to two aspects: first, it provides the necessary mathematical background for each of the new extensions of FCA that is discussed, and second, it discusses applications for each extension. This paper provides a summary of the trends and applications of FCA after 2011. Further, the paper also provides pointers to most authoritative literature on FCA. To achieve this, we have collected 544 articles from prominent indexing systems.

\section{Survey methodology}

This systematic study has been conducted with the help of research papers published after 2011. The rationale 
behind is that the summary of FCA findings till 2011 was analyzed in a series of papers by Poelmans et al. (2013a; 2013b; 2014). A total of 544 research papers have been collected from the prominent indexing systems such as Scopus, Google Scholar, leading scientific data bases such as the ACM Digital Library, IEEE Xplore, ScienceDirect, SpringerLink, etc. Also, we have referred to the proceedings of prominent FCA conferences like ICFCA, ICCS, CLA, etc.

The methodology we have used to extract the articles is based on the following keywords: formal concept analysis (FCA), formal concept, fuzzy formal concept, concept lattice, fuzzy concept lattice and Galois connection. From the 544 collected papers we have shortlisted 352 works based on their innovative content. From these papers the following research trends identified: (a) FCA with granular computing, (b) FCA with a fuzzy setting, (c) FCA with an interval-valued fuzzy setting, (d) FCA with possibility theory, (e) FCA with rough set theory, (f) triadic concept analysis in a fuzzy setting, (g) factor concepts, and (h) concept lattices of incomplete data.

\section{Formal concept analysis}

In this section we provide a brief background of FCA, its tools and current research issues.

3.1. Background. FCA is a mathematical model for knowledge processing tasks. It receives data, structured in the form of objects, attributes and the relation between them. This relation is represented as in the form of a formal context $-\mathbf{F}=(X, Y, R)$ where $X$ is a set of objects, $Y$ is a set of attributes and $R$ is a binary relation between them, of Table 1 (where $a, b, c, \ldots, o$ represent the attributes $y_{1}, y_{2}, \ldots, y_{15}$, respectively). From the given context, FCA derives a set of objects $(A)$ and the set of all attributes $(B)$ that are in common for these objects. Similarly, the dual operation on the set of attributes $(B)$ identifies the common objects objects $(A)$ using the concept forming operator.

Definition 1. (Concept forming operators) The operators $\uparrow: 2^{X} \rightarrow 2^{Y}$ and $\downarrow: 2^{Y} \rightarrow 2^{X}$ are defined for every $A \subseteq X$ and $B \subseteq Y$ by:

$$
\begin{aligned}
& A^{\uparrow}=\{y \in Y \mid \forall x \in A:(x, y) \in R\}, \\
& B^{\downarrow}=\{x \in X \mid \forall y \in B:(x, y) \in R\},
\end{aligned}
$$

where $A^{\uparrow}$ is the set of all attributes shared by all objects from $A$. Similarly, $B^{\downarrow}$ is the set of all objects sharing all attributes from $B$. The formal concept is a pair $(A, B)$ of $A \subseteq X$ and $B \subseteq Y$ such that $A^{\uparrow}=B$ and $B^{\downarrow}=A$. The collection of all such pairs of concepts forms a concept lattice under the closure operation.
Definition 2. (Concept lattice) The concept lattice structure determines the hierarchy of formal concepts which follows the partial ordering principle: $\left(A_{1}, B_{1}\right) \leq$ $\left(A_{2}, B_{2}\right)$ iff $A_{1} \leq A_{2}\left(B_{2} \leq B_{1}\right)$ and provides generalization and specialization between the concepts, i.e., $\left(A_{1}, B_{1}\right)$ is more specific than $\left(A_{2}, B_{2}\right)\left(\left(A_{2}, B_{2}\right)\right.$ is more general). The attributes of each formal concept are inherited from the most general maximum node, while the objects are inherited from the most specific minimum node. Several algorithms have been proposed for generating the concept lattice (Bartl et al., 2011; Codocedo et al., 2011; Kuznetsov and Obiedkov, 2002; Outrata and Vychodil, 2012) including parallel and recursive algorithms (Fu and Mephu Nguifo, 2004; Krajca et al., 2008; Langdon et al., 2011). The attribute implications are represented in the form of $A \rightarrow B$ over the set $Y$ (Ganter and Wille, 1999). There are several patents granted for the inventions that are based on FCA. Table 2 summarizes some of such patents.

3.2. Tools and ssoftware in FCA. Several tools and packages are developed to handle the FCA tasks such as generating concepts, attribute implications, etc. (http: / /www. upriss.org.uk/fca/fca.html). Following is a summary of some of the available tools:

1. ToscanaJ: Provides a view for conceptual schemas and optimized for a non-technical audience, http: //toscanaj.sourceforge.net/.

2. ConExp: Implements the basic functionality of FCA with a crisp setting, http: / / conexp.sourceforge.net/.

3. ConExp-NG: Is an extension of ConExp with the focus on usability and maintainability, https://github.com/fcatools/ conexp-ng.

4. Conexp-clj: Allows us to handle the formal context, relational algebra with formal contexts, many-valued contexts, attribute exploration, lattice layouts by NextClosure or Iceberg Concepts and fuzzy FCA, https://github.com/exot/conexp-clj/

5. Galicia: Is an open environment and handles binary and relational contexts,

http: / / www.iro.umontreal.ca/ galicia/.

6. FcaStone: Is a command-line utility that converts between the file formats of commonly used FCA tools (such as ToscanaJ, ConExp and Galicia) or FCA formats to other graphics formats (dot, fig, svg, ...), http: / / fcastone.sourceforge.net/ 
Table 1. Binary formal context.

\begin{tabular}{|c|c|c|c|c|c|c|c|c|c|c|c|c|c|c|c|}
\hline & $a$ & $b$ & $c$ & $d$ & $e$ & $f$ & $g$ & $h$ & $i$ & $j$ & $k$ & $l$ & $m$ & $n$ & $o$ \\
\hline \hline$x_{1}$ & $\mathrm{x}$ & & $\mathrm{x}$ & & & $\mathrm{x}$ & & $\mathrm{x}$ & & $\mathrm{x}$ & & & & & $\mathrm{x}$ \\
$x_{2}$ & $\mathrm{x}$ & & & $\mathrm{x}$ & & $\mathrm{x}$ & & $\mathrm{x}$ & & $\mathrm{x}$ & & & & & $\mathrm{x}$ \\
$x_{3}$ & $\mathrm{x}$ & & $\mathrm{x}$ & & & $\mathrm{x}$ & & $\mathrm{x}$ & & & $\mathrm{x}$ & & & & $\mathrm{x}$ \\
$x_{4}$ & $\mathrm{x}$ & & $\mathrm{x}$ & & $\mathrm{x}$ & & & $\mathrm{x}$ & & $\mathrm{x}$ & & $\mathrm{x}$ & $\mathrm{x}$ & & \\
$x_{5}$ & $\mathrm{x}$ & & $\mathrm{x}$ & & $\mathrm{x}$ & & & $\mathrm{x}$ & & & $\mathrm{x}$ & $\mathrm{x}$ & $\mathrm{x}$ & & \\
$x_{6}$ & $\mathrm{x}$ & & & $\mathrm{x}$ & & $\mathrm{x}$ & & $\mathrm{x}$ & & & & & & $\mathrm{x}$ & $\mathrm{x}$ \\
$x_{7}$ & $\mathrm{x}$ & & & $\mathrm{x}$ & $\mathrm{x}$ & & $\mathrm{x}$ & & $\mathrm{x}$ & & & & & $\mathrm{x}$ & \\
$x_{8}$ & & $\mathrm{x}$ & & $\mathrm{x}$ & & & & $\mathrm{x}$ & & & & & & $\mathrm{x}$ & \\
\hline
\end{tabular}

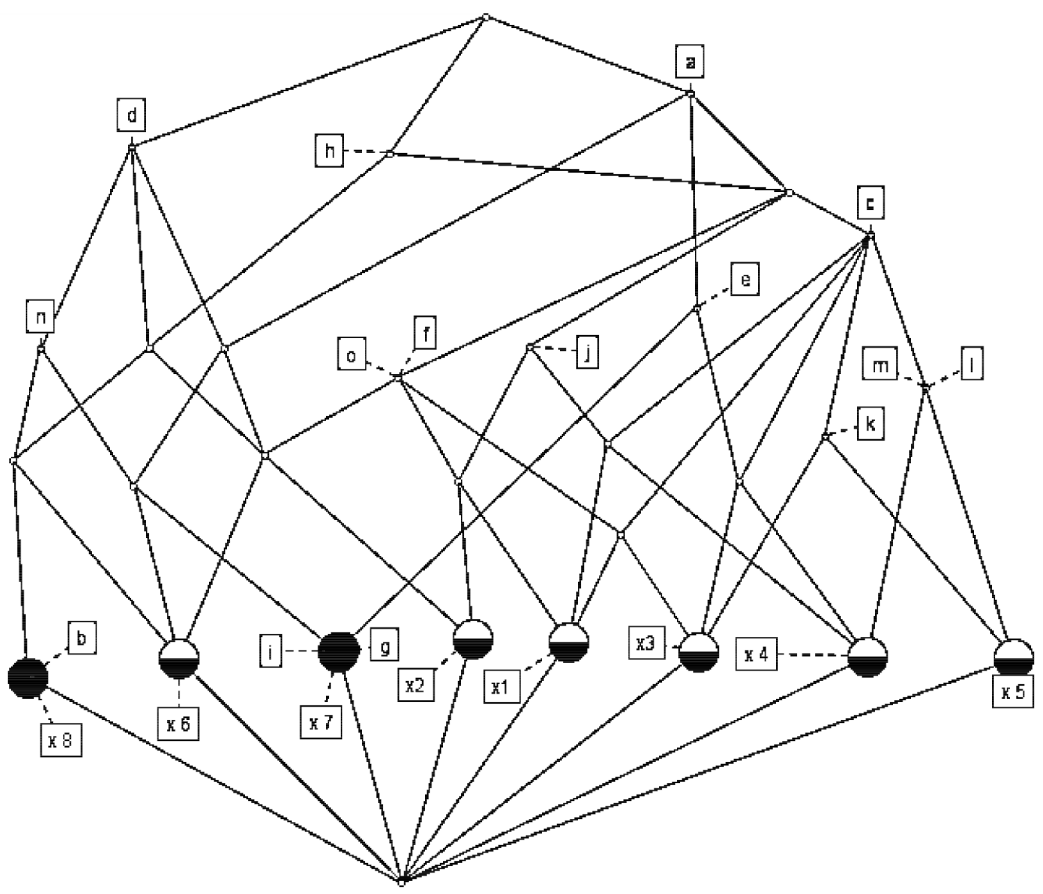

Fig. 1. Formal concept lattice for the context shown in Table 1.

7. Lattice Navigator: Provides three applications of FCA using a single setup file: Lattice Navigator, Context Editor, Lattice Visualizer, http: //www.fca.radvansky.net/
news.php.

8. Colibri-concepts: Permits to explore only part of a concept lattice which is most useful when working with huge lattices,

\section{http://code.google.com/p/colibri -concepts/.}

3.3. Issues in FCA. Hierarchical order visualization of formal concepts in the concept lattice structure is an important concern for practical applications of FCA (Aswani Kumar, 2011a). In this process, one of the major issues is the size of the concept lattice constructed from "a large formal context" (Codocedo et al., 2011; Aswani Kumar et al., 2015a; Aswani Kumar and Srinivas, 2010;
Singh and Gani, 2015). The concept lattice constructed from the large context becomes complex and impractical. Hence, handling a large formal context and reducing the size of the concept lattice are addressed as real issues in practical applications of FCA (Dias and Vieira, 2015; Singh et al., 2015a; 2015b).

The issue includes a number of formal concepts, and implications generated from a large context can be exponential while counting them is $P$-complete and $P$-hard (Babin and Kuznetsov, 2013; Bartl et al., 2011; Bazhanov and Obiedkov, 2014; Obiedkov, 2012; Slezak, 2012). This problem also merges with a fuzzy formal context (Denniston et al., 2013; Ma and Zhang, 2013), a decision formal context ( $\mathrm{Li}$ et al., 2012a; 2012b) multi adjoint concept lattices (Medina and Ojeda-Aciego, 2012; Medina, 2012a; 2012b), and granular computing (Tadrat et al., 2012; Yang et al., 2011a). Subsequently, some metrics are proposed to measure the stability 
and importance of obtained concepts (Kuznetsov, 2013; Martin et al., 2013; Pei et al., 2013). In the next section we illustrate the mathematics behind each of the above categorized research trends in FCA with an illustrative example.

\section{Current research trends in FCA}

In this section we describe trends of FCA such as granular computing, FCA with a fuzzy setting, an interval-valued fuzzy setting, possibility theory, a rough setting, a triadic setting, factor concepts and the incomplete context.

4.1. FCA with granular computing. In this section we discuss a method for reducing the concepts at a chosen granulation of their (computed) weight (Butka et al., 2012; Lei and Tian, 2012; Ma and Zhang, 2013).

Table 2. Some important patents on FCA and their inventions.

\begin{tabular}{|c|c|}
\hline Patent information & Invention \\
\hline $\begin{array}{l}\text { US patent (May 19,2005) } \\
\text { US2005/0108252A1 }\end{array}$ & $\begin{array}{c}\text { Attribute } \\
\text { implications }\end{array}$ \\
\hline $\begin{array}{l}\text { US patent (May 25,2006) } \\
\text { US2006/0112108A1 }\end{array}$ & $\begin{array}{l}\text { Information } \\
\text { retrieval }\end{array}$ \\
\hline $\begin{array}{l}\text { US patent (Sep 21,2006) } \\
\text { US2006/0212470A1 }\end{array}$ & $\begin{array}{l}\text { Organizing } \\
\text { the information }\end{array}$ \\
\hline $\begin{array}{c}\text { International patent(April 5,2007) } \\
\text { WO2007/038375A2 }\end{array}$ & $\begin{array}{c}\text { Processing } \\
\text { patient records }\end{array}$ \\
\hline $\begin{array}{l}\text { US patent (Jul 7,2007) } \\
\text { US2005/0149510A1 }\end{array}$ & $\begin{array}{l}\text { Mapping of } \\
\text { context }\end{array}$ \\
\hline $\begin{array}{l}\text { US patent (Jun 10,2010) } \\
\text { US2010/0153092A1 }\end{array}$ & $\begin{array}{l}\text { Identifying } \\
\text { similar word }\end{array}$ \\
\hline $\begin{array}{l}\text { China patent (April 6,2011) } \\
\text { CN2017885100 }\end{array}$ & $\begin{array}{c}\text { Dynamic } \\
\text { mining system }\end{array}$ \\
\hline $\begin{array}{c}\text { China patent (Aug 24,2011) } \\
\text { CN101699444B }\end{array}$ & $\begin{array}{l}\text { Remote } \\
\text { sensing }\end{array}$ \\
\hline $\begin{array}{l}\text { US patent (Jan 5,2012) } \\
\text { US2012/0005210A1 }\end{array}$ & $\begin{array}{l}\text { To structure } \\
\text { a database }\end{array}$ \\
\hline $\begin{array}{c}\text { International patent (Feb 2,2012) } \\
\text { WO2012014938A1 }\end{array}$ & $\begin{array}{l}\text { Electronic } \\
\text { repository }\end{array}$ \\
\hline $\begin{array}{l}\text { China patent (Jun 20,2012) } \\
\text { CN102508767A }\end{array}$ & $\begin{array}{c}\text { FCA based } \\
\text { software maintenance }\end{array}$ \\
\hline $\begin{array}{c}\text { US patent(Feb 26,2013) } \\
\text { US8386489B2 }\end{array}$ & $\begin{array}{l}\text { Conceptual } \\
\text { similarity }\end{array}$ \\
\hline $\begin{array}{c}\text { China patent (May 29,2013) } \\
\text { CN103123607A }\end{array}$ & $\begin{array}{c}\text { Software } \\
\text { maintenance }\end{array}$ \\
\hline $\begin{array}{c}\text { China patent (Jun 26,2013) } \\
\text { CN103176902A }\end{array}$ & $\begin{array}{c}\text { Software } \\
\text { error locations }\end{array}$ \\
\hline $\begin{array}{l}\text { US patent (Jul 25, 2013) } \\
\text { US20130191735A1 }\end{array}$ & $\begin{array}{c}\text { Sentiments } \\
\text { analysis }\end{array}$ \\
\hline $\begin{array}{l}\text { US patent(Aug 1,2013) } \\
\text { US2013/0198195A1 }\end{array}$ & $\begin{array}{c}\text { Resume } \\
\text { classification }\end{array}$ \\
\hline $\begin{array}{c}\text { European patent (Oct 2,2013) } \\
\text { EP2645274A1 }\end{array}$ & $\begin{array}{l}\text { Reducing } \\
\text { the lattice }\end{array}$ \\
\hline $\begin{array}{c}\text { International patent WO } 2014 \\
\text { 013327A1 (Jan23,2014) }\end{array}$ & $\begin{array}{c}\text { Traffic } \\
\text { measurement }\end{array}$ \\
\hline
\end{tabular}

The reason is that the number of concepts increases exponentially in the worst case. In this case, granular computing provides a path to process the large context into less time based on the requirement when dealing with numeric processing (Pedrycz, 2013). An information granule is the basic notion of granular computing, which can be defined broadly as a collection of information. This notion has been recently introduced into the concept lattice as an attempt to decrease the computation time (Belohlavek et al., 2013; Wu et al., 2009; 2012; Li et al., 2015; Xu and Li, 2015). In general, the information granule regarded as a collection of elements drawn together by their closeness (resemblance, proximity, functionality, etc.) articulated in terms of some useful spatial (Ciobanu and Vaideanu, 2014; Singh and Gani, 2015; Singh and Aswani Kumar, 2015a; Aswani Kumar et al., 2015a), bidrectional (Aswani Kumar et al., 2015b), temporal (Belohlavek and Trnecka, 2013; Dias et al., 2013; Dias and Vieira, 2013), or functional relationships (Singh and Aswani Kumar, 2012b; Vityaev et al., 2012; Zhang et al., 2012). Selecting the level to find some important concepts in the large context is based on user requirements.

Definition 3. (Granular concept) Information granularity has been engaged in one way or another in quantifying the lack of numeric precision computed by different methods. The computed weight $(w)$ of any given concepts indicates the importance of attributes $(Y)$ where $0 \leq w \leq 1$. This process gives the priority to the concepts whose weight is more than the chosen threshold $\theta(0 \leq \theta \leq 1)$ (Belohlavek and Macko, 2011; Babin and Kuznetsov, 2012).

Example 1. For illustration of the granular based concept lattice, a context shown in Table 1 has been considered (Junli et al., 2013). Let us analyse any object $x_{j} \in X$ of a given context and compute its probability $P\left(y_{j} / x_{i}\right)$ for possessing the corresponding attribute $y_{i}$. Then the average information weight $E\left(y_{i}\right)$, of $x_{i}$ to provide the attribute $y_{i} \in Y$ can be computed as follows (and shown in Tables 3 and 4) (Junli et al., 2013):

$$
E\left(y_{i}\right)=-\sum_{i=1}^{m} P\left(y_{i} / x_{j}\right) \log _{2}\left(P\left(y_{i} / x_{j}\right)\right),
$$

where $m$ represents the total number of attributes

$$
\begin{gathered}
w_{i}=\frac{E\left(y_{i}\right)}{\sum_{i=1}^{m} E\left(y_{i}\right)} \\
W \operatorname{eight}(B)=\frac{\sum\left(w_{i}\right)}{m},
\end{gathered}
$$

where $B$ is the intent.

The removal of formal concepts at a chosen granulation is shown in Table 5. Subsequently, it can be applied to FCA with fuzzy attributes as well (Singh et al., 2015a; Xu and Li, 2015). 
4.2. FCA with a fuzzy setting. FCA has been extended with a fuzzy setting for handling vagueness and uncertainty in data using the following definitions.

Definition 4. (Fuzzy formal context) It is a triplet $\mathbf{K}=$ $(X, Y, \tilde{R})$, where $X$ is a set of objects, $Y$ is a set of attributes and $\tilde{R}$ is an $L$-relation: $X \times Y \rightarrow L$.

Definition 5. (Residuated lattice) A residuated lattice $\mathbf{L}=(L, \wedge, \vee, \otimes, \rightarrow, 0,1)$ is the basic structure of truth degrees, and it is complete iff (i) $(L, \wedge, \vee, 0,1)$ is a complete lattice, (ii) $(L, \otimes, 1)$ is commutative monoid, (iii) $\otimes$ and $\rightarrow$ are adjoint operators, i.e., $a \otimes b \leq c$ iff

Table 3. Computed weight for each attributes of Table 1.

\begin{tabular}{|c|c|c|c|}
\hline$y_{i}$ & $\mathrm{P}\left(y_{i}\right)$ & $\mathrm{E}\left(y_{i}\right)$ & $w_{i}$ \\
\hline \hline$a$ & 0.875 & 0.169 & 0.026 \\
$b$ & 0.125 & 0.375 & 0.057 \\
$c$ & 0.500 & 0.500 & 0.076 \\
$d$ & 0.500 & 0.500 & 0.076 \\
$e$ & 0.375 & 0.531 & 0.081 \\
$f$ & 0.500 & 0.500 & 0.076 \\
$g$ & 0.125 & 0.375 & 0.057 \\
$h$ & 0.875 & 0.169 & 0.026 \\
$i$ & 0.125 & 0.375 & 0.057 \\
$j$ & 0.375 & 0.531 & 0.081 \\
$k$ & 0.250 & 0.500 & 0.076 \\
$l$ & 0.250 & 0.500 & 0.076 \\
$m$ & 0.250 & 0.500 & 0.076 \\
$n$ & 0.375 & 0.531 & 0.081 \\
$o$ & 0.500 & 0.500 & 0.076 \\
\hline
\end{tabular}

Table 4. Computed weight and deviation for each concepts of Fig. 1.

\begin{tabular}{|c|c|c|c|c|}
\hline Node & Intent & Average & $W(B)$ & $D(y)$ \\
\hline \hline$c_{0}$ & $\oslash$ & 1 & 1 & 0 \\
$c_{1}$ & $a$ & 0.026 & 0.026 & 0 \\
$c_{2}$ & $d$ & 0.76 & 0.076 & 0 \\
$c_{3}$ & $h$ & 0.026 & 0.026 & 0 \\
$c_{4}$ & $a e$ & 0.054 & 0.054 & 0.055 \\
$c_{5}$ & $a h$ & 0.026 & 0.026 & 0 \\
$c_{6}$ & $a d$ & 0.051 & 0.051 & 0.0326 \\
$c_{7}$ & $a c h$ & 0.043 & 0.043 & 0.029 \\
$c_{8}$ & $a d n$ & 0.061 & 0.061 & 0.031 \\
$c_{9}$ & dhn & 0.061 & 0.061 & 0.031 \\
$c_{10}$ & acfho & 0.056 & 0.056 & 0.028 \\
$c_{11}$ & adfho & 0.056 & 0.056 & 0.028 \\
$c_{12}$ & adein & 0.064 & 0.064 & 0.024 \\
$c_{13}$ & bdghn & 0.059 & 0.059 & 0.022 \\
$c_{14}$ & acfhjo & 0.060 & 0.060 & 0.027 \\
$c_{15}$ & adfhjo & 0.060 & 0.060 & 0.027 \\
$c_{16}$ & acfhko & 0.059 & 0.059 & 0.026 \\
$c_{17}$ & adfhno & 0.060 & 0.060 & 0.027 \\
$c_{18}$ & acehjlm & 0.063 & 0.063 & 0.026 \\
$c_{19}$ & acehklm & 0.063 & 0.063 & 0.025 \\
$c_{20}$ & abcdefghijklmno & 1 & 1 & 0 \\
\hline
\end{tabular}

$a \leq b \rightarrow c, \forall a, b, c \in L$ and defined distinctly (Davey and Priestley, 2002; Macko, 2013).

Definition 6. (Fuzzy Galois connection) For any L-set $A \in L^{X}$ of objects, and $B \in L^{Y}$ of attributes we can define an $\mathbf{L}$-set of $A^{\uparrow} \in L^{Y}$ attributes and $\mathbf{L}$-set $B^{\downarrow} \in$ $L^{X}$ of objects as follows (Belohlavek and Vychodil, 2012; Pocs, 2012):

$$
\begin{aligned}
& \text { 1. } A^{\uparrow}(y)=\bigwedge_{x \in X}(A(x) \rightarrow \tilde{R}(x, y)), \\
& \text { 2. } B^{\downarrow}(x)=\bigwedge_{y \in Y}(B(y) \rightarrow \tilde{R}(x, y)) .
\end{aligned}
$$

Definition 7. (Fuzzy formal concept) It is a pair of $(A, B) \in L^{X} \times L^{Y}$ satisfying $A^{\uparrow}=B$ and $B^{\downarrow}=A$, where $A$ is called the (fuzzy) extent and $B$ is called the (fuzzy) intent.

Example 2. For illustration, we have considered a fuzzy context shown in Table 6. For concept generation and lattice structure, the interested readers can refer to the works of Belohlavek and Vychodil (2005), Kaiser and Schmidt (2013), Kang et al. (2012a), Martin and Majidian (2013) or Martin et al. (2013).

Definition 8. (Implication) Implication over a attribute set $Y$ is an expression $A \Rightarrow B$, where $A, B \subseteq L^{Y}$. It represents "if it is (very) true that an object has all attributes from $A$, then it has also all attributes from $B$ (Massanet et al., 2013; Glodeanu, 2012). The notions

Table 5. Removed concepts at chosen granulation.

\begin{tabular}{|c|c|c|}
\hline$W(B)$ & $\theta$ & Removed concepts \\
\hline \hline 1 & $0.076<\theta \leq 1$ & $c_{1}, c_{2}, c_{3}, c_{4}, c_{5}, c_{6}, c_{7}$ \\
& & $c_{8}, c_{9}, c_{10}, c_{11}, c_{12}$, \\
& & $c_{13}, c_{14}, c_{15}, c_{17}, c_{18}, c_{19}$ \\
0.076 & $0.064<\theta \leq 0.076$ & $c_{1}, c_{3}, c_{4}, c_{5}, c_{6}, c_{7}$, \\
& & $c_{8}, c_{9}, c_{10}, c_{11}, c_{12}, c_{13}$, \\
& & $c_{14}, c_{15}, c_{17}, c_{18}, c_{19}$ \\
0.64 & $0.063<\theta \leq 0.064$ & $c_{1}, c_{3}, c_{4}, c_{5}, c_{6}, c_{7}$, \\
& & $c_{8}, c_{9}, c_{10}, c_{11}, c_{13}, c_{14}$, \\
& & $c_{15}, c_{17}, c_{18}, c_{19}$ \\
0.063 & $0.061<\theta \leq 0.063$ & $c_{1}, c_{3}, c_{4}, c_{5}, c_{6}$, \\
& & $c_{7}, c_{8}, c_{9}, c_{10}, c_{11}$, \\
0.061 & $0.060<\theta \leq 0.061$ & $c_{13}, c_{14}, c_{15}, c_{17}$ \\
& & $c_{1}, c_{3}, c_{4}, c_{5}, c_{6}, c_{7}, c_{10}$, \\
0.06 & $0.059<\theta \leq 0.06$ & $c_{11}, c_{13}, c_{14}, c_{15}, c_{17}$ \\
& & $c_{1}, c_{3}, c_{4}, c_{5}, c_{6}$, \\
0.059 & $0.056<\theta \leq 0.059$ & $c_{7}, c_{10}, c_{11}, c_{13}$ \\
& & $c_{1}, c_{3}, c_{4}, c_{5}, c_{6}$, \\
0.056 & $0.054<\theta \leq 0.056$ & $c_{7}, c_{10}, c_{11}$ \\
0.054 & $0.051<\theta \leq 0.054$ & $c_{1}, c_{3}, c_{4}, c_{5}, c_{6}, c_{7}$ \\
0.051 & $0.043<\theta \leq 0.051$ & $c_{1}, c_{3}, c_{5}, c_{6}, c_{7}$ \\
0.043 & $0.026<\theta \leq 0.043$ & $c_{1}, c_{3}, c_{5}, c_{7}$ \\
0.026 & $0<\theta \leq 0.026$ & $c_{1}, c_{3}, c_{5}$ \\
& & $\oslash$ \\
\hline
\end{tabular}


"being very true", "to have an attribute" and logical connective "if-then" are determined by the chosen $L$ (Belohlavek et al., 2013b; Zhai et al., 2012; 2013; Massanet, 2013).

Example 3. Table 6 generate following implications (i) $(s, 0.5 / l, f) \rightarrow(s, l, f, n)$, (ii) $(0.5 / s, 0.5 / n) \rightarrow(s, n)$, (iii) $(l, f) \rightarrow(l, f, 0.5 / n)$, (iv) $(0.5 / l) \rightarrow(0.5 / l, f)$, (v) $(f, 0.5 / n) \rightarrow(l, f, 0.5 / n)$ (vi) $(n) \rightarrow(s, n)$. These six attribute implications are sufficient to determine all the fuzzy formal concepts generated from Table 6.

Recently many researchers focused on the analysis of a fuzzy context having similar attributes set (Alcalde $e t$ al., 2012a; 2012b; 2015; Li and Mi, 2013).

Example 4. For illustration, two fuzzy contexts having a similar attribute set are shown in Tables 7 and 8, with CS: Computer science, AC: Accounting, ME: Mechanical, CK: Cooking, and $C_{1}, \ldots, C_{5}$ representing candidates. The context shown in Table 7 and 8 can be connected using the composition $\tilde{R}_{1} * \tilde{R}_{2}=\tilde{R}_{3}$ as shown in Table 9. For the employment of Waiter most of the candidates are eligible, where $C_{2}$ is more suitable having membership value 1 (Singh and Aswani Kumar, 2015b; Tho et al., 2006; Wang and $\mathrm{Xu}, 2011$ ).

Table 6. Fuzzy formal context.

\begin{tabular}{|c|c|c|c|c|}
\hline & \multicolumn{2}{|c|}{ Size } & \multicolumn{2}{c|}{ Distance } \\
\cline { 2 - 5 } & small (s) & large (1) & far (f) & near(n) \\
\hline \hline Mercury $(\mathrm{Me})$ & 1 & 0 & 0 & 1 \\
$\operatorname{Venus}(\mathrm{Ve})$ & 1 & 0 & 0 & 1 \\
Earth $(\mathrm{Ea})$ & 1 & 0 & 0 & 1 \\
Mars $(\mathrm{Ma})$ & 1 & 0 & 0.5 & 1 \\
Jupiter $(\mathrm{Ju})$ & 0 & 1 & 1 & 0.5 \\
Saturn $(\mathrm{Sa})$ & 0 & 1 & 1 & 0.5 \\
Uranus $(\mathrm{Ur})$ & 0.5 & 0.5 & 1 & 0 \\
Neptune $(\mathrm{Ne})$ & 0.5 & 0.5 & 1 & 0 \\
Pluto $(\mathrm{Pl})$ & 1 & 0 & 1 & 0 \\
\hline
\end{tabular}

Table 7. Requirements of knowledge for employment in a company: $\tilde{R}_{1}$.

\begin{tabular}{|c|c|c|c|c|}
\hline & CS & AC & ME & CK \\
\hline \hline Domestichelper & 0.1 & 0.3 & 0.1 & 1.0 \\
Waiter & 0.0 & 0.4 & 0.0 & 0.7 \\
Accountant & 0.9 & 1.0 & 0.0 & 0.0 \\
Carsalesman & 0.5 & 0.7 & 0.9 & 0.0 \\
\hline
\end{tabular}

Table 8. Knowledge of candidate for employment: $\tilde{R}_{2}$.

\begin{tabular}{|c|c|c|c|c|}
\hline & CS & AC & ME & CK \\
\hline \hline$C_{1}$ & 0.5 & 0.8 & 0.3 & 0.6 \\
$C_{2}$ & 0.2 & 0.5 & 0.1 & 1.0 \\
$C_{3}$ & 0.0 & 0.2 & 0.0 & 0.3 \\
$C_{4}$ & 0.9 & 0.4 & 0.1 & 0.5 \\
$C_{5}$ & 0.7 & 0.5 & 0.2 & 0.1 \\
\hline
\end{tabular}

4.3. FCA with an interval valued fuzzy setting. For adequate analysis of fuzzy attributes, FCA has been extended to an interval-valued fuzzy setting as described below (Singh and Aswani Kumar, 2012a).

Definition 9. (Interval number) It is an $D-\left[a^{-}, b^{+}\right]$with $0 \leq a^{-} \leq b^{+} \leq 1$. For interval numbers $D_{1}=\left[a_{1}^{-}, b_{1}^{+}\right]$ and $D_{2}=\left[a_{2}^{-}, b_{2}^{+}\right]$, we can define $(D[0,1], \leq, \vee, \wedge)$ is a complete lattice with $[0,0]$ as the least element and $[1,1]$ as the greatest element.

Definition 10. (Interval-valued fuzzy set) An interval-valued fuzzy set $I$ in $V$ is defined as

$$
I=\left\{\left(v,\left[\mu_{I}^{-}(v), \mu_{I}^{+}(v)\right]\right): v \in V\right\},
$$

where $\mu_{I}^{-}(v)$ and $\mu_{I}^{+}(v)$ are fuzzy subsets of $V$ such that $\mu_{I}^{-}(v) \leq \mu_{I}^{+}(v)$ for all $v \in V$. For interval-valued fuzzy sets $I=\left[\mu_{I}^{-}(v), \mu_{I}^{+}(v)\right]$ and $J=\left[\mu_{J}^{-}(v), \mu_{J}^{+}(v)\right]$ in $V$ we can define

- $I \cup J=\left(v, \max \left(\mu_{I}^{-}(v)\right), \mu_{J}^{-}(v)\right), \max \left(\mu_{I}^{+}(v)\right.$, $\left.\left.\mu_{J}^{+}(v)\right)\right)$, where, $v \in V$;

- $I \cap J=\left(v, \min \left(\mu_{I}^{-}(v)\right), \mu_{J}^{-}(v)\right), \min \left(\mu_{I}^{+}(v)\right.$, $\left.\left.\mu_{J}^{+}(v)\right)\right)$, where $v \in V$.

Definition 11. (Fuzzy graph) A fuzzy graph $G=$ $(V, \mu, \rho)$ is a non-empty set $V$ together with a pair of functions $\mu: V \rightarrow[0,1]$ and $\rho: V \times V \rightarrow[0,1]$, such that, for all $v_{1}, v_{2}$ in $V, \rho\left(v_{1}, v_{2}\right) \leq \mu\left(v_{1}\right) \wedge \mu\left(v_{2}\right)$, where $\mu$ is said to be the fuzzy vertex set and $\rho$ is the fuzzy edges set of $\mathrm{G}$.

Definition 12. (Interval-valued fuzzy graph) An interval-valued fuzzy graph of a graph $\mathrm{G}$, is a pair $(I, J)$ where $I=\left[\mu_{I}^{-}, \mu_{I}^{+}\right]$is an interval-valued fuzzy set on $V$ and $J=\left[\mu_{J}^{-}, \mu_{J}^{+}\right]$is an interval valued fuzzy relation on the set $E$ such that

$$
\begin{gathered}
\mu_{J}^{-}(p q) \leq \min \left(\mu_{I}^{-}(p), \mu_{I}^{-}(q)\right), \\
\mu_{J}^{+}(p q) \leq \min \left(\mu_{I}^{+}(p), \mu_{I}^{+}(q)\right)
\end{gathered}
$$

for all $p q \in E$.

Example 5. Suppose that $V=\{p, q, r\}$ and $E=$ $\{p q, q r, r p\}$. Let $I$ be an interval-valued fuzzy set of $V$ and $J$ be an interval-valued fuzzy set of $E \subseteq V \times V$ defined by

$$
I=\{(p / 0.2, q / 0.3, r / 0.4),(p / 0.4, q / 0.5, r / 0.6)\},
$$

Table 9. Composition of fuzzy contexts: $\tilde{R}_{3}=\tilde{R}_{1} * \tilde{R}_{2}$.

\begin{tabular}{|c|c|c|c|c|c|}
\hline & $C_{1}$ & $C_{2}$ & $C_{3}$ & $C_{4}$ & $C_{5}$ \\
\hline \hline Domestichelper & 0.6 & 1.0 & 0.3 & 0.5 & 0.1 \\
Waiter & 0.9 & 1.0 & 0.6 & 0.8 & 0.4 \\
Accountant & 0.6 & 0.3 & 0.1 & 0.4 & 0.5 \\
Carsalesman & 0.4 & 0.2 & 0.5 & 0.2 & 0.3 \\
\hline
\end{tabular}




$$
\begin{aligned}
J=\{ & (p q / 0.1, q r / 0.2, r p / 0.1), \\
& (p q / 0.3, q r / 0.4, r p / 0.4)\} .
\end{aligned}
$$

Then it can be presented in an interval-valued fuzzy graph as shown in Fig. 2 (Akram and Dudek, 2011).

Definition 13. (Complete graph) An interval-valued fuzzy graph $G$ is complete if

$$
\mu_{J}^{-}(p q)=\min \left(\mu_{I}^{-}(p), \mu_{I}^{-}(q)\right)
$$

and

$$
\mu_{J}^{+}(p q)=\min \left(\mu_{I}^{+}(p), \mu_{I}^{+}(q)\right),
$$

for all $p q \in E$.

Example 6. Consider graph $G=(V, E)$ such that $V=$ $(p, q, r), E=(p q, q r, r p)$ and $I, J$ are defined as follows:

$$
\begin{gathered}
I=((p / 0.2, q / 0.3, r / 0.4),(p / 0.4, q / 0.5, r / 0.5)) ; \\
J=((p q / 0.2, q r / 0.3, r p / 0.2) \\
(p q / 0.4, q r / 0.5, r p / 0.4)) .
\end{gathered}
$$

Then $G=(I, J)$ is an interval-valued fuzzy complete graph.

Definition 14. The composition, join, and product of two interval-valued fuzzy graphs G1 and G2 are again an interval-valued fuzzy graph.

Example 7. (Interval-valued fuzzy context) It is a triplet $(X, Y, \mathbf{I})$ where $X$ represents objects, $Y$ represents attributes and $\mathbf{I}$ represents interval-valued fuzzy relation:

$$
\mathbf{I}=\left\{\left((x, y),\left[\mu_{\tilde{I}}^{-}(x, y), \mu_{\tilde{I}}^{+}(x, y)\right]\right):(x, y) \in X \times Y\right\}
$$

(cf. Alcalde et al., 2011). As an example we have considered a context shown in Table 10 (Djouadi and Prade, 2009).

Definition 15. (Interval-valued fuzzy concept) (Singh et al., 2015b) It is a pair $\left(\left(x_{i}\right.\right.$, $\left.\left.\left[\mu_{\tilde{R}}^{-}(x), \mu_{\tilde{R}}^{+}(x)\right]\right),\left(y_{j},\left[\mu_{\tilde{R}}^{-}(y), \mu_{\tilde{R}}^{+}(y)\right]\right)\right), \quad$ which satisfies $\left(x_{i},\left[\mu_{\tilde{R}}^{-}(x), \mu_{\tilde{R}}^{+}(x)\right]\right)=(\operatorname{subb}(y))^{\downarrow}$ and $\left(y_{j},\left[\mu_{\tilde{R}}^{-}(y), \mu_{\tilde{R}}^{+}(y)\right]\right)=(\operatorname{subb}(x))^{\uparrow}$, where $s u b b$ is used for subset (Djouadi, 2011). For example, the following interval-valued fuzzy formal concepts can be generated from Table 10 (Singh and Aswani Kumar, 2014):

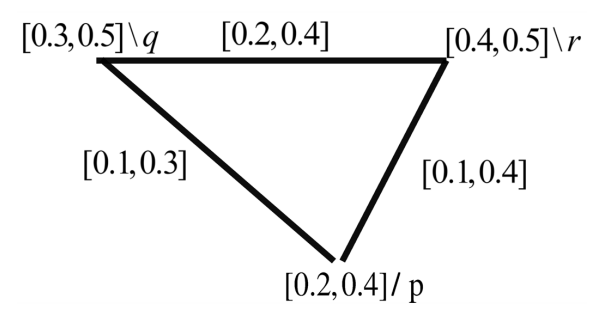

Fig. 2. Interval-valued fuzzy graph for Example 5.
1. $\left\{\oslash,[1.0,1.0] / y_{1}+[1.0,1.0] / y_{2}+[1.0,1.0] / y_{3}\right\}$,

2. $\left\{[0.9,1.0] / x_{1}+[0.8,1.0] / x_{2}+[0.3,0.6] / x_{3}+\right.$ $\left.[0.2,0.4] / x_{4},[1.0,1.0] / y_{1}\right\}$,

3. $\left\{[0.5,0.7] / x_{1}+[0.0,1.0] / x_{2}+[1.0,1.0] / x_{3}+\right.$ $\left.[0.6,1.0] / x_{4},[1.0,1.0] / y_{2}\right\}$,

4. $\left\{[0.0,0.2] / x_{1}+[0.5,0.5] / x_{2}+[0.8,0.8] / x_{3}+\right.$ $\left.[0.0,0.1] / x_{4},[1.0,1.0] / y_{3}\right\}$,

5. $\left\{[0.5,1.0] / x_{1}+[0.0,1.0] / x_{2}+[0.3,1.0] / x_{3}+\right.$ $\left.[0.2,1.0] / x_{4},[1.0,1.0] / y_{1}+[1.0,1.0] / y_{2}\right\}$,

6. $\left\{[0.0,1.0] / x_{1}+[0.5,1.0] / x_{2}+[0.3,0.8] / x_{3}+\right.$ $\left.[0.0,0.4] / x_{4},[1.0,1.0] / y_{1}+[1.0,1.0] / y_{3}\right\}$,

7. $\left\{[0.0,0.2] / x_{1}+[0.0,1.0] / x_{2}+[0.8,1.0] / x_{3}+\right.$ $\left.[0.0,1.0] / x_{4},[1.0,1.0] / y_{2}+[1.0,1.0] / y_{3}\right\}$,

8. $\left\{[1.0,1.0] / x_{1}+[1.0,1.0] / x_{2}+[1.0,1.0] / x_{3}+\right.$ $\left.[1.0,1.0] / x_{4}, \oslash\right\}$.

The interval-valued fuzzy concept lattice for the above generated concepts is shown in Fig. 3. This extension has been successfully applied in information retrieval and the rule mining tasks (Zerarga and Djouadi, 2013; Zhai et al., 2012).

4.4. FCA with possibility theory. FCA is augmented with possibility theory for handling uncertainty in data. In this section, we provide a summary of the four basic set-functions of possibility theory in terms of FCA. The possibility distribution $\pi$, defined on a universe $U$, is equated to the characteristic (membership) function of a fuzzy set $H$ in $U$ and the two set-functions $(S, T)$ are associated with $\pi$ as follows (Dubois and Prade, 2012).

Definition 16. (Potential possibility) A possibility measure is $\pi: \pi(S)=\max _{s \in S} \pi(s)$. It estimates to what extent event $S$ is consistent with the information represented by $\pi$ and characterized by $\pi(S \cup T)=$

Table 10. Interval-valued fuzzy formal context.

\begin{tabular}{|c|c|c|c|}
\hline & $y_{1}$ & $y_{2}$ & $y_{3}$ \\
\hline \hline$x_{1}$ & {$[0.9,1.0]$} & {$[0.5,0.1]$} & {$[0.0,0.2]$} \\
$x_{2}$ & {$[0.8,1.0]$} & {$[0.0,1.0]$} & {$[0.5,0.5]$} \\
$x_{3}$ & {$[0.3,0.6]$} & {$[1.0,1.0]$} & {$[0.8,0.8]$} \\
$x_{4}$ & {$[0.2,0.4]$} & {$[0.6,1.0]$} & {$[0.0,0.1]$} \\
\hline
\end{tabular}


$\max (\pi(S), \pi(T))$, where as $\pi(\oslash)=0$ if $\pi(s)$ is normalized (i.e., there exists $\pi(U)=1$ ). However, in the Boolean case (the set $H$ is non empty and crisp), $\pi(S)=1$ iff $S \cap H \neq \oslash$, otherwise 0 .

Definition 17. (Actual necessity) It expresses the necessity (certainty) an event is true as the opposite event is more impossible as follows: $N(S)=1-$ $\pi\left(S^{-}\right)=1-\max _{s \notin S} \pi(s)$, where $\notin S=U / S$. $N(S)$ estimates to what extent event $S$ is implied by the information $H$ represented by $\pi$ and characterized by decomposition property $N(S \cap T)=\min (N(S), N(T))$ whereas $N(\oslash)=0$ if $N$ is normalized (i.e., there exists $N(U)=1)$. However, in the Boolean case $N(A)=1$ iff $\oslash \neq H \subseteq A$, otherwise 0 .

Definition 18. (Actual possibility) A measure of "actual (or guaranteed) possibility" $\Delta(S)=\max _{s \in S} \pi(s)$. It estimates to what extent all elements in $S$ are possible and characterized by $\Delta(S \cup T)=\min (\Delta(S), \Delta(T))$, whereas $\Delta(\oslash)=1$ by convention (hence $\Delta \leq \pi$ and $\Delta(U)=0$ if $\pi$ is anti-normalized (i.e., there exists $u$ such that $\pi(u)=$ 0 ). However, in the Boolean case, $\Delta(A)=1$ iff $S \subset H$ (if $H \neq U$ ), otherwise 0 .

Definition 19. (Potential necessity) A dual measure of "potential necessity or certainty" $\nabla(S)=1-\nabla\left(S^{-}\right)=$ $1-\max _{s \notin S} \pi(s)$, which estimates to what extent there exists at least one value in the complement of $S$ that has a zero (or more generally a low) degree of possibility and is characterized by $\nabla(S \cup T)=\max (\nabla(S), \nabla(T))$ whereas $\nabla(\oslash)=1$ if $\pi$ is anti-normalized and $\nabla(U)=0$. However, in the Boolean case, $\nabla(S)=1$ iff $S \cap H \neq U$, otherwise 0 .

The above operators can be combined with each other in a meaningful way in a formal context $K=$ $(X, Y, R)$ as follows:

1. $X^{\pi}$ is the set of objects that satisfy at least one attributes in $Y$.

$$
\begin{aligned}
X^{\pi} & =\{x \in X \mid Y \cap R(x) \neq \oslash\} \\
& =\{x \in X \mid \exists y \in Y: x R y \neq \oslash\} .
\end{aligned}
$$

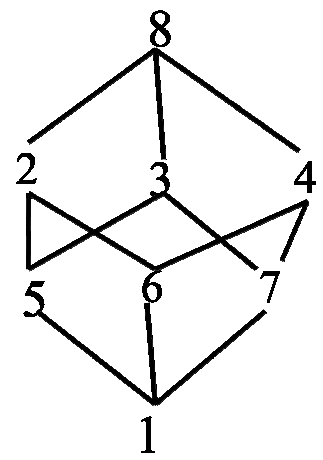

Fig. 3. Interval-valued fuzzy concept lattice of Table 10.
2. $X^{N}$ is the set of objects such that any objects satisfied by one of them is necessarily in $Y$ :

$$
\begin{aligned}
X^{N} & =\{x \in X \mid R(x) \subset Y\} \\
& =\{x \in X \mid \forall y \in Y:(x R y \Rightarrow y \neq Y)\} .
\end{aligned}
$$

3. $X^{\Delta}$ is the set of objects that satisfy all attributes in $Y$ :

$$
\begin{aligned}
X^{\Delta} & =\{x \in X \mid \forall y \in Y(y \in y \Rightarrow x R y\} \\
& =\{x \in X \mid Y \subset R(x)\} .
\end{aligned}
$$

4. $X^{\nabla}$ is the set of objects that do not satisfy at least one attributes in $Y^{-}$.

$$
\begin{aligned}
X^{\nabla} & =\{x \in X \mid Y \cup R(x) \neq X\} \\
& =\left\{x \in X \mid \exists y \in Y^{-}: x R^{-} y\right\} .
\end{aligned}
$$

Definition 20. (Derivational operator) The derivational operators are defined in an $L$-context for the fuzzy set $\tilde{Y}$ $\in L^{Y}\left(\tilde{X} \in L^{X}\right)$

(i) $\tilde{X}^{\delta}(x)=\wedge_{x \in X}(\tilde{X}(x) \rightarrow R(x, y))$,

(ii) $\tilde{X}^{\pi}(x)=\bigvee_{x \in X}(\tilde{X}(x) * R(x, y))$,

(iii) $\left.\tilde{X}^{N}(x)=\wedge_{x \in X}(R(x, y) \rightarrow \tilde{(} X)(x)\right)$,

(iv) $\tilde{X}^{\nabla}(x)=\vee_{x \in X}(-\tilde{X}(x) *-R(x, y))$,

where $\rightarrow$ denotes a fuzzy implication and $*$ denotes a fuzzy conjunction.

Definition 21. (Formal concept with possibility theory) It is a pair $(\tilde{X}, \tilde{Y})$ such that $\tilde{X}^{\Delta}=\tilde{Y}$ and $\tilde{Y}^{\Delta}=\tilde{X}$ (similarly for other operators), and it follows the infimum and supremum property given by

$$
\begin{aligned}
& \bigwedge_{j \in J}\left(X_{j}, Y_{j}\right)=\left(\bigcap_{j \in J} X_{j},\left(\bigcup_{j \in J} Y_{j}\right)^{\Delta \Delta}\right), \\
& \bigwedge_{j \in J}\left(X_{j}, Y_{j}\right)=\left(\left(\bigcup_{j \in J} X_{j}\right)^{\Delta \Delta}, \bigcap_{j \in J} Y_{j}\right) .
\end{aligned}
$$

4.5. FCA with rough set theory. Rough set theory (RST) deals with uncertainty and imperfect knowledge. It was introduced in FCA by Yao (2004) and Yao et al. (2012).

Definition 22. (Approximation operator) The dual approximation operators ${ }^{\circ}$ and ${ }^{\Delta}: 2^{X} \rightarrow 2^{Y}$ can be defined as below:

$$
\begin{aligned}
X^{\circ} & =\{y \in Y \mid \forall x \in X(x I Y \Rightarrow x \in X)\} \\
& \left.=\left\{y \in Y \mid I_{y} \subseteq X\right)\right\} .
\end{aligned}
$$




$$
\begin{aligned}
X^{\Delta} & =\{y \in Y \mid \exists x \in X(x I Y \wedge x \in X)\} \\
& \left.=\left\{y \in Y \mid I_{y} \cap X \neq \oslash\right)\right\}=\bigcup_{x \in X} x I .
\end{aligned}
$$

Similarly, other pairs of approximation operators ${ }^{\circ}$ and ${ }^{\Delta}: 2^{Y} \rightarrow 2^{X}$ can be defined as below:

$$
\begin{aligned}
Y^{\circ} & =\{x \in X \mid \forall y \in Y(x I Y \Rightarrow y \in Y)\} \\
& =\{y \in Y \mid x I \subseteq Y)\} . \\
Y^{\Delta} & =\{x \in X \mid \exists y \in Y(x I Y \wedge y \in Y)\} \\
& =\{x \in X \mid x I \cap Y \neq \oslash)\}=\bigcup_{y \in Y} I y .
\end{aligned}
$$

Based on the above notions, two new concept lattices in rough set theory can be introduced as follows.

Definition 23. (Object and attribute oriented concept) A pair $(A, B), A \subseteq X, B \subseteq Y$ is called an object oriented concept if $X=Y^{\Delta}$ and $Y=X^{\circ}$. The set of all object oriented formal concepts forms a lattice. Specifically, the meet $\wedge$ and join $\vee$ are defined by

$$
\begin{aligned}
& \left(x_{1}, y_{1}\right) \wedge\left(x_{2}, y_{2}\right)=\left(\left(y_{1} \cap y_{2}\right)^{\Delta}, y_{1} \cap y_{2}\right), \\
& \left(x_{1}, y_{1}\right) \vee\left(x_{2}, y_{2}\right)=\left(x_{1} \cup x_{2},\left(x_{1} \cup x_{2}\right)^{\circ}\right) .
\end{aligned}
$$

Similarly, a pair $(A, B), A \subseteq X, B \subseteq Y$ is called an attribute oriented concept if $X=Y^{\circ}$ and $Y=X^{\Delta}$. All the generated property oriented formal concepts form a lattice. Specifically, the meet $\wedge$ and join $\vee$ are defined by

$$
\begin{aligned}
& \left(x_{1}, y_{1}\right) \wedge\left(x_{2}, y_{2}\right)=\left(\left(x_{1} \cap x_{2}, x_{1} \cap x_{2}\right)^{\Delta}\right), \\
& \left(x_{1}, y_{1}\right) \vee\left(x_{2}, y_{2}\right)=\left(\left(y_{1} \cup y_{2}\right)^{\circ},\left(y_{1} \cup y_{2}\right)\right) .
\end{aligned}
$$

Example 8. For illustration, we have considered a formal context shown in Table 11. The object oriented concepts

Table 11. Formal context.
\begin{tabular}{|c|c|c|c|c|c|}
\hline & $y_{1}$ & $y_{2}$ & $y_{3}$ & $y_{4}$ & $y_{5}$ \\
\hline \hline$x_{1}$ & $\times$ & & $\times$ & $\times$ & $\times$ \\
$x_{2}$ & $\times$ & & $\times$ & & \\
$x_{3}$ & & $\times$ & & & $\times$ \\
$x_{4}$ & & $\times$ & & & $\times$ \\
$x_{5}$ & $\times$ & & & & \\
$x_{6}$ & $\times$ & $\times$ & & & $\times$ \\
\hline
\end{tabular}

generated from Table 11 are

1. $\left\{\left(x_{1}, x_{2}, x_{3}, x_{4}, x_{5}, x_{6}\right),\left(y_{1}, y_{2}, y_{3}, y_{4}, y_{5}\right)\right\}$,

2. $\left\{\left(x_{1}, x_{2}, x_{5}, x_{6}\right),\left(y_{1}, y_{3}, y_{4}\right)\right\}$,

3. $\left\{\left(x_{1}, x_{2}, x_{3}, x_{6}\right),\left(y_{2}, y_{3}, y_{4}, y_{5}\right)\right\}$,

4. $\left\{\left(x_{1}, x_{2}\right),\left(y_{3}, y_{4}\right)\right\}$,

5. $\left\{\left(x_{1}, x_{3}, x_{4}, x_{6}\right),\left(y_{2}, y_{4}, y_{5}\right)\right\}$,
6. $\left\{\left(x_{1}\right),\left(y_{4}\right)\right\}$,

7. $\left\{\left(x_{3}, x_{4}, x_{5}\right),\left(y_{2}\right)\right\}$,

8. $\{\oslash, \oslash\}$.

Similarly, the attribute oriented formal concepts generated from Table 11 are

1. $\left\{\left(x_{1}, x_{2}, x_{3}, x_{4}, x_{5}, x_{6}\right),\left(y_{1}, y_{2}, y_{3}, y_{4}, y_{5}\right)\right\}$,

2. $\left\{\left(x_{2}, x_{3}, x_{4}, x_{5}, x_{6}\right),\left(y_{1}, y_{2}, y_{3}, y_{5}\right)\right\}$,

3. $\left\{\left(x_{1}, x_{2}, x_{5}\right),\left(y_{1}, y_{3}, y_{4}, y_{5}\right)\right\}$,

4. $\left\{\left(x_{3}, x_{4}, x_{5}, x_{6}\right),\left(y_{1}, y_{2}, y_{5}\right)\right\}$,

5. $\left\{\left(x_{2}, x_{5}\right),\left(y_{1}, y_{3}\right)\right\}$,

6. $\left\{\left(x_{3}, x_{4}\right),\left(y_{2}, y_{5}\right)\right\}$,

7. $\left\{x_{5}, y_{1}\right\}$,

8. $\{\oslash, \oslash\}$,

where $\oslash$ represents the null set.

The object and attribute oriented concept lattices are shown in Figs. 4 and 5, respectively. These two concept lattices differ in representations of the involved subsets of objects and their attributes. Recently, this extension has been applied in several research domains (Ganter and Meschke, 2011; Yang et al., 2011b; Kang et al., 2012b; Slezak, 2012; Wang and Li, 2012; Yang, 2011; Zhao and Liu, 2011) as well as for concept approximation (Chen et al., 2015; Saquer and Deogun, 2001).

4.6. Triadic concept analysis in a fuzzy setting. Extension to a triadic context handles more attributes or conditional attributes in a crisp as well as a fuzzy setting.

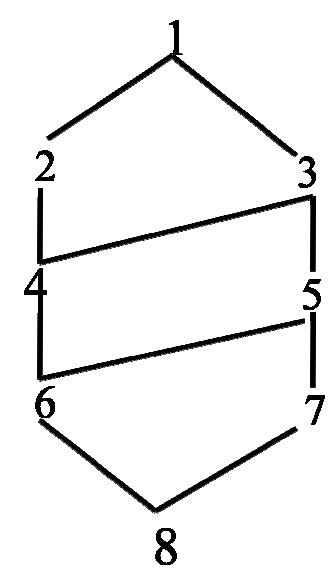

Fig. 4. Object oriented concept lattice of Table 11. 
Definition 24. (Triadic context) It is defined as a quadruple $K=(X, Y, Z, \tilde{I})$, where $X$ represents a set of objects, $Y$ represents a set of attributes and $Z$ represents a set of conditions, i.e, if $(x, y, z) \in \tilde{I}$ means object $x$ has attribute $y$ under condition $z$, whereas in the case of fuzzy attributes $I$ represents the relationship among them using fuzzy membership-value. From a triadic context, the number of dyadic contexts can be derived as follows (Ignatov et al., 2015): Given a fuzzy set $C_{k} \in L^{X_{k}}$, $K$ induces a dyadic fuzzy context $K_{C_{k}}^{i j}=\left(X_{i}, Y_{j}, \tilde{I}_{C_{k}}^{i j}\right)$, where $I_{C_{k}}^{i j}$ is defined by (Belohlavek and Osicka, 2012a).

$$
\tilde{I}_{C_{k}}^{i j}\left(x_{i}, y_{j}\right)=\bigwedge_{z_{k} \in Z_{k}} C_{k}\left(x_{k}\right) \rightarrow \tilde{I}\left(x_{i}, y_{j}, z_{k}\right) .
$$

The pair $\left(x_{i}, y_{j}\right) \in \tilde{I}_{C_{k}}^{i j}$ iff for each $x_{k} \in X_{k}$ implies $\left(x_{i}, y_{j}, z_{k}\right) \in \tilde{I}$. The concept forming operator can be induced by a dyadic context $K_{C_{k}}^{i j}$, i.e., for a fuzzy set $C_{i} \in L^{X_{i}}$ we can define a fuzzy set $C_{C_{k}}^{i, j} \in L^{Y_{j}}=$ $\wedge_{x_{i} \in X_{i}} C_{i}\left(x_{i}\right) \rightarrow \tilde{I}_{C_{k}}^{i j}\left(x_{i}, y_{j}\right)$.

Definition 25. (Triadic fuzzy concepts) It is a triplet ( $\left.A_{1}, A_{2}, A_{3}\right)$ consisting of fuzzy sets $A_{1} \in L^{X}, A_{2} \in$ $L^{Y}, A_{3} \in L^{Z}$ such that $A_{i}=A_{j}^{i, j, A_{k}}, A_{j}=A_{k}^{j, k, A_{i}}$, and $A_{k}=A_{i}^{k, i, A_{j}}$ and can be shown in the concept trilattice.

Example 9. For illustration, a triadic context shown in Table 12 is considered, where objects (Beef Steak, Cheese Salad, Vegetable Plate and Fried Chicken Wings) represent dishes; attributes (Taste: T, Aroma: A, Look: L, and Price: P) represent features of the dishes; customers (Fry, Bender, Leela, Zoidberg) represent evaluation of the dishes (Belohlavek and Osicka, 2012b). The degree 0 stands for bad, 1/2 for neutral and 1 for excellent. Table 13 depicts five triadic fuzzy concepts generated from the context shown in Table 12, which provide the following information: Concept No. 1 represents customers who evaluate taste and aroma of beaf steak and fried chicken

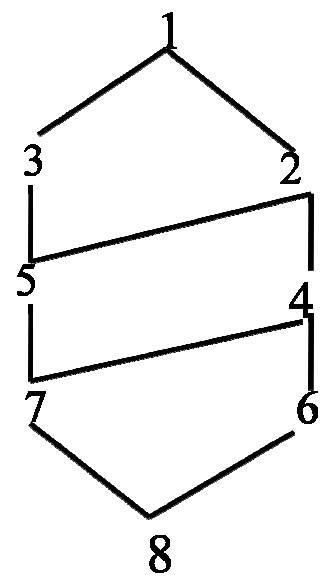

Fig. 5. Property oriented concept lattice of Table 11. wings as excellent whereas their look is evaluated as neutral. Concept No. 2 represents that customers who like salad for its excellent taste, aroma and look, whereas its price evaluates as neutral. Concept No. 3 represents customers having no preferences in food. Concept No. 4 represents customers who like beef steak and partly fried chicken wings for their excellent taste and look and at least neutral aroma. Concept No. 5 shows that there is no customer who finds all properties of given dishes excellent.

4.7. Factor concepts. In this section, data analysis using factor concepts is described (Belohlavek, 2012; Ganter and Glodeanu, 2012; Glodeanu and Ganter, 2012; Glodeanu, 2011).

Definition 26. (Factor concepts) A subset of formal concepts $F$ generated from the given formal context $\mathbf{F}$ such that $\bigcup_{(A, B) \in F(A \times B)}=R$ is called factorization. If $F$ is minimal with respect to its cardinality, then it is called

Table 12. Triadic fuzzy formal context

\begin{tabular}{|c|c|c|c|c|c|}
\hline & & Steak & Salad & Veg & Wings \\
\hline \hline \multirow{6}{*}{ Fry } & Taste & 1 & 0.5 & 0 & 1 \\
& Aroma & 1 & 0 & 0 & 1 \\
& Look & 1 & 0.5 & 0.5 & 0.5 \\
& Price & 0 & 0.5 & 1 & 0.5 \\
& Taste & 1 & 0 & 0 & 1 \\
& Aroma & 1 & 0 & 0 & 1 \\
& Look & 1 & 0.5 & 0 & 0.5 \\
& Price & 0.5 & 0 & 0 & 1 \\
& Taste & 0.5 & 1 & 0.5 & 0 \\
& Aroma & 0 & 1 & 0 & 0 \\
& Look & 0.5 & 1 & 0.5 & 0 \\
& Price & 0 & 1 & 0 & 0.5 \\
& Taste & 1 & 1 & 1 & 1 \\
& Aroma & 1 & 1 & 1 & 1 \\
& Look & 1 & 1 & 1 & 1 \\
& Price & 0 & 0.5 & 0 & 0.5 \\
\hline \multirow{7}{*}{ Zoidberg }
\end{tabular}

Table 13. Five triadic fuzzy concepts generated from Table 12.

\begin{tabular}{|c|c|c|c|c|c|}
\hline & 1 & 2 & 3 & 4 & 5 \\
\hline \hline Steak & 1 & 0 & 1 & 1 & 1 \\
Salad & 0 & 1 & 1 & 0 & 1 \\
Vegetable & 0 & 0 & 1 & 0 & 1 \\
Wings & 1 & 0 & 1 & 0.5 & 1 \\
Taste & 1 & 1 & 1 & 1 & 1 \\
Aroma & 1 & 1 & 1 & 0.5 & 1 \\
Look & 0.5 & 1 & 1 & 1 & 1 \\
Price & 0 & 0.5 & 0 & 0 & 1 \\
Fry & 1 & 0 & 0 & 1 & 0 \\
Bender & 1 & 0 & 0 & 1 & 0 \\
Leila & 0 & 1 & 0 & 0 & 0 \\
Zoidberg & 1 & 1 & 1 & 1 & 0 \\
\hline
\end{tabular}


an optimal factorization. The elements of $F$ are called (optimal) factors. Then $O(X, Y, R) \cap A(X, Y, R) \subseteq$ $F$ are called mandatory factors, where $O(X, Y, R)$ and $A(X, Y, R)$ are the sets of object and attribute concepts, respectively.

The idea of finding factor concepts is based on the set covering problem.

Example 10. Let $U=\{1,2,3,4,5,6,7,8,9,10\}$, $V=\{2,4,6,8,10\}, P=(\{1,2\},\{2,3\},\{4,5\}$, $\{6,7,8\},\{9,10\},\{1,3,5\},\{2,4\},\{4,6\},\{8,9,10\})$.

- $C=\{\{1,2\},\{8,9,10\}\}$ is not a covering of $V$ because $\bigcup C \neq V$.

- $C=\{\{1,2\},\{2,3\},\{4,5\},\{6,7,8\},\{9,10\}\}$ is a covering of $V$ because $\bigcup C=V$. But $C$ is not minimal because there exist coverings of $V$ which contain smaller number of sets.

- $C=\{\{2,4\},\{6,7,8\},\{9,10\}\}$ is a minimal covering of $V$ because $\bigcup C=V$ and no other covering has smaller numbers of sets than 3 .

- $C=\{\{2,4\},\{4,6\},\{8,9,10\}\}$.

Example 11. As an example, a context shown in Table 14 can be considered, with the following abbreviations: $g$ (gas and dust), $y$ (young stars), $o$ (old stars), $s$ (spiral arms), $b$ (bulge), $m$ (minimal star formation). The formal concepts generated from Table 14 are shown in Table 15. The matrix shown in Table 14 can be decomposed into a Boolean matrix $\bigcup_{(A, B) \in F(A \times B}=I$ such that $|F| \leq|Y|$.

Definition 27. (Mandatory concepts) These are object and attribute concepts, investigated as follows: $O(X, Y, R)=\left(\left\{c_{1}, c_{2}, c_{3}, c_{4}\right\}\right.$ and $A(X, Y, R)=$ $\left(\left\{c_{1}, c_{2}, c_{4}, c_{5}, c_{6}\right\}\right.$.

The object concepts in Table 15 are $O(X, Y, R) \cap$ $O(X, Y, R)=\left\{c_{1}, c_{2}, c_{4}\right\}$. The object concepts are those formal concepts which we are looking for the analysis. We can observe that these concepts $\left\{c_{1}, c_{2}, c_{4}\right\}$ do not

Table 14. Formal context of Galaxy types and their properties.

\begin{tabular}{|c|c|c|c|c|c|c|}
\hline Galaxies & $g$ & $y$ & $o$ & $s$ & $b$ & $m$ \\
\hline \hline 1. Milky Way & $\times$ & $\times$ & $\times$ & $\times$ & $\times$ & \\
2. Virgo A & & & $\times$ & & & $\times$ \\
3. M 82 & $\times$ & $\times$ & & & $\times$ & \\
4. M 83 & & $\times$ & & & & \\
5. M 85 & $\times$ & $\times$ & $\times$ & $\times$ & $\times$ & \\
6. M 102 & & & $\times$ & & $\times$ & \\
7. M 105 & & & $\times$ & & & $\times$ \\
\hline
\end{tabular}

cover the incidence induced by the objects 5 and 6 . These objects can be covered by $c_{3}, c_{5}$ and $c_{6}$, as shown in Table 15. However, the obtained set of concepts with $c_{5}$ and $c_{6}$ would not be a minimal subset with respect to cardinality. Finally, optimal factor $F$ includes $\left(\left\{c_{1}, c_{2}, c_{3}, c_{4}\right\}\right.$, which decompose the matrices $(7 \times 6)$ shown in Table 13 into two $7 \times 4$ and $4 \times 7$ matrices to be analyzed in a 4-dimensional space of factors instead of describing the galaxies in a 7-dimensional space. Recently, some applications of factor concepts have been shown in FCA with a fuzzy setting also (Belohlavek et al., 2013a; 2011b; Bartl et al., 2011; Ignatov et al., 2015; Yao et al., 2012) as well as in graph theory (Helmi et al., 2014).

4.8. FCA with incomplete data. In this section, we provide a discussion on handling incomplete data (Simiński, 2012).

Definition 28. (Incomplete context) (Krajca et al., 2012; Li et al., 2013a; Simiński, 2012) An incomplete L-context is a triplet $=(X, Y, R)$, where $X$ and $Y$ are sets and $R$ : $X \times Y \rightarrow L$ such that $R \subseteq U \cup\{0,1\}$. An ordinary context is the completion of a given relation.

Example 12. For illustration, we have considered an incomplete context shown in Table 16 , where $u_{1}$ and $u_{2}$ represent the unknown values, and $u_{1} \leq u_{2}$. Three possible contexts are shown in Tables 17-19. Their corresponding lattices are shown in Figs. 6-8.

Definition 29. (Incomplete fuzzy context) Let $U=$ $\left\{u_{1}, u_{2}, \ldots, u_{k}\right\}$ be the set of variables and $V\left(\subseteq 2^{U}\right)$ a set of assignments representing known dependencies between the variables. Then we can find the minimal residuated lattice $\mathbf{K}(U \cup L)$ for the set of admissible assignments $V$. An incomplete $L$-context with variables $\left\{u_{1}, u_{2}, \ldots, u_{k}\right\}$

Table 15. Formal concepts generated from the context shown in

\begin{tabular}{|c|c|c|}
\hline$C_{i}$ & Table 14. & Descriptions \\
\hline \hline$C_{0}$ & $(\oslash, Y)$ & empty concept \\
$C_{1}$ & $(\{1,4\},\{g, y, o, s, b\})$ & spiral galaxy \\
$C_{2}$ & $(\{2,7\},\{o, m\})$ & elliptic galaxy \\
$C_{3}$ & $(\{1,4,5,6\},\{o, b\})$ & lenticular galaxy \\
$C_{4}$ & $(\{1,3,4\},\{g, y, b\})$ & irregular galaxy \\
$C_{5}$ & $(\{1,2,4,5,6,7\},\{o\})$ & galaxy with old stars \\
$C_{6}$ & $(\{1,3,4,5,6\},\{b\})$ & galaxy with bulge \\
$C_{7}$ & $(X, \oslash)$ & universal concept \\
\hline
\end{tabular}

Table 16. Incomplete formal context.

\begin{tabular}{|c|c|c|c|c|c|}
\hline & $y_{1}$ & $y_{2}$ & $y_{3}$ & $y_{4}$ & $y_{5}$ \\
\hline \hline$x_{1}$ & & & $\times$ & $\times$ & \\
$x_{2}$ & $u_{1}$ & $\times$ & $u_{2}$ & $\times$ & \\
$x_{3}$ & $\times$ & $\times$ & $\times$ & & \\
$x_{4}$ & & $\times$ & & & \\
\hline
\end{tabular}


is a formal context $(X, Y, \tilde{R})$, where $\tilde{R}$ can take values

Table 17. Possible complete formal context for Table 16.

\begin{tabular}{|c|c|c|c|c|c|}
\hline & $y_{1}$ & $y_{2}$ & $y_{3}$ & $y_{4}$ & $y_{5}$ \\
\hline \hline$x_{1}$ & & & $\times$ & $\times$ & \\
$x_{2}$ & & $\times$ & & $\times$ & \\
$x_{3}$ & $\times$ & $\times$ & $\times$ & & \\
$x_{4}$ & & $\times$ & & & \\
\hline
\end{tabular}

Table 18. Second possible complete formal context for Table 16

\begin{tabular}{|c|c|c|c|c|c|}
\hline & $y_{1}$ & $y_{2}$ & $y_{3}$ & $y_{4}$ & $y_{5}$ \\
\hline \hline$x_{1}$ & & & $\times$ & $\times$ & \\
$x_{2}$ & & $\times$ & $\times$ & $\times$ & \\
$x_{3}$ & $\times$ & $\times$ & $\times$ & & \\
$x_{4}$ & & $\times$ & & & \\
\hline
\end{tabular}

Table 19. Third possible complete formal context for Table 16.

\begin{tabular}{|c|c|c|c|c|c|}
\hline & $y_{1}$ & $y_{2}$ & $y_{3}$ & $y_{4}$ & $y_{5}$ \\
\hline \hline$x_{1}$ & & & $\times$ & $\times$ & \\
$x_{2}$ & $\times$ & $\times$ & $\times$ & $\times$ & \\
$x_{3}$ & $\times$ & $\times$ & $\times$ & & \\
$x_{4}$ & & $\times$ & & & \\
\hline
\end{tabular}

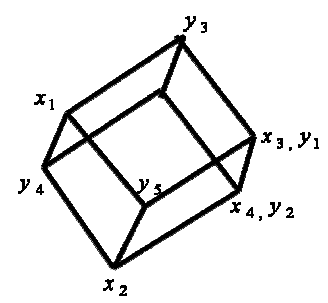

Fig. 6. Concept lattice for Table 17.

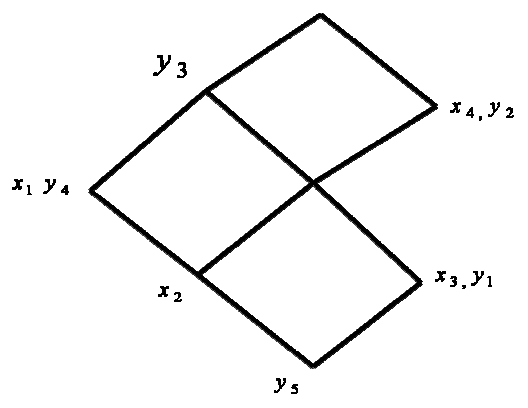

Fig. 7. Concept lattice for Table 18.

Table 20. Incomplete fuzzy formal context.

\begin{tabular}{|l|c|c|c|}
\hline & $y_{1}$ & $y_{2}$ & $y_{3}$ \\
\hline \hline$x_{1}$ & 0.5 & 0.0 & 0.5 \\
$x_{2}$ & $u_{1}$ & 1.0 & 0.0 \\
$x_{3}$ & 0.0 & $u_{2}$ & 0.5 \\
$x_{4}$ & 0.0 & 1.0 & 1.0 \\
\hline
\end{tabular}

from $L$ and $U: \tilde{R}(X \times Y) \subseteq U \cup L$. This means that the formal context contains only elements of $L$ and the variables. Hence, for this purpose we can define a map for $v: U \rightarrow \mathbf{L}$, where $\mathbf{L}$ is a residuated lattice.

Example 13. For illustration, an incomplete context shown in Table 20 is considered containing values from an $L$ context $=\{0.0,0.5,1.0\}$, and the set of variables $u_{1}$, $u_{2}$ varies between $0.0,0.5$ and 1.0. Hence, the context can take values from $\{0.0,0.5,1.0\}$ and represent them as a complete fuzzy context.

\section{Applications of FCA}

This section summarizes the applications of FCA reported in the literature after 2011. Tables 21-24 provide this summary. From these tables we can conclude that FCA has attracted applications in several domains due to its potential of knowledge discovery (Aswani Kumar, 2011a; 2011b; Aswani Kumar and Singh, 2014), representation (Iordache, 2011; Poelmans et al., 2013a; 2014), reasoning (Rainer and Ganapati, 2011; Ruairi, 2013; Sebastien et al., 2013) and the decision context (Li et al., 2011a; 2011b; Shao et al., 2014) which contains another tuple called a set of decision attributes (Yang et al., 2011a). Ontology engineering is an another research direction regarding relations between individuals and classes. FCA has been applied to identify important groups of individuals that responded similarly to peer-identified experts (Alqadah and Bhatnagar, 2012; Codocedo et al., 2012; Chen et al., 2011; Formica, 2012; Fowler, 2013; Junli et al., 2013; Senatore and Pasi, 2013; Tadrat et al., 2012; Tho et al., 2006). Recently, several researchers have shown the application of formal concepts in description logic for improving the knowledge representation task (Atif et al., 2014; Borgwardt and Penaloza, 2014; Distel, 2012; Denniston et al., 2013; Pei et al., 2013; Wu et al., 2012). Description logic discounts the structural representation of knowledge consisting of

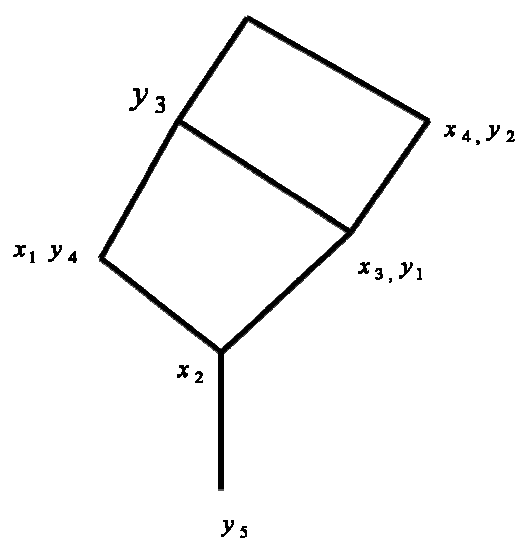

Fig. 8. Concept lattice for Table 19. 
the terminological part (TBox) and the assertional part (ABox). Subsequently, hierarchical order visualization between the entity and its relations in a conceptual graph using FCA has been discussed (Croitorua et al., 2012; Li and Guo, 2013; Nguyen et al., 2011; Nguyen and Yamamoto, 2012; Yu et al., 2013; Annapurna and Aswani Kumar, 2013).

FCA has been used for handling relational structures in the source code and dependency between software parts in several aspects including RBAC (Priss, 2011; 2012; Priss et al., 2012; 2013). Role based access control (RBAC) provides the role of a user in the IT systems with specific permissions like read or write. Designing RBAC using FCA has been discussed by Aswani Kumar (2013). The technique to identify unexpected and potential effects caused by software changes and their impact analysis using FCA is developed by Korei (2013) and Li et al. (2013c).

A gene expression dataset is a many-valued context in which each row corresponds to a gene and each column to a sample, and the attribute (expression) values indicate the abundance of mRNA in a sample (Muszyński and Osowski, 2013), http: / / indianalgae.co.in. Hence the patterns of gene data have been studied after the scaled context using FCA by Kaytoue et al. (2011a). FCA has been applied for mining the common hypermethylated genes between breast cancer subtypes by Amin et al. (2012) and Bouaud et al. (2013). Endres et al. (2012) have applied FCA to read the semantic information obtained from fMRI Bold responses using FCA. The ingredients of FCA with mathematical morphology and description logics have been combined for image processing tasks by Atif et al. (2014). We observe that some of the researchers have tried to analyze the sentiments of people using FCA (emotions, love, preference) (Li and Tsai, 2013; Antoni et al., 2014). The word opinion or preference shows two sides: one is acceptation and another is non-acceptation, which may mold the concept lattice for bipolar information visualization (Singh and Aswani Kumar, 2014).

"Big data" and their analysis attracted the attention of some researchers using FCA to find the pattern structure and its visualization (Biao et al., 2012; Kuznetsov, 2013; Radvansky et al., 2013). Subsequently, in cloud computing, allocating resources to users using FCA has been discussed by Sarnovsky et al. (2012).

\section{Conclusions}

In this paper we aimed at analyzing the current research trends in FCA based on innovations reported in more than 350 papers published after 2011. We can observe that FCA has received significant attention of researchers for knowledge discovery and representation tasks. Subsequently, FCA is extended into different
Table 21. Some important applications of FCA in the KDD process and ontology engineering.

\begin{tabular}{|c|c|}
\hline KDD process & Research goal \\
\hline Alcalde et al., 2012c & Finding temporal patterns \\
\hline Alqadah and Bhatnagar, 2012 & Mining similar concepts \\
\hline Aswani Kumar, 2011b & Knowledge discovery \\
\hline Aswani Kumar, 2012 & Rule mining \\
\hline Belohlavek et al., 2011a & IPAQ questionnaires \\
\hline Belohlavek et al., 2013b & Background knowledge \\
\hline Dau, 2013 & Analyzing a triple store \\
\hline Fowler, 2013 & Order in taxonomy \\
\hline Galitsky et al., 2013 & Pattern on parse thickets \\
\hline Macko, 2013 & Fuzzy FCA \\
\hline Missaoui and $\mathrm{Ku}$ & Triadic rules \\
\hline Nguyen et al., 2011 & Mathematical search \\
\hline Nguyen and Yamamoto, 2012 & Learning from graph \\
\hline Li et al., 2011b & Symbolic data analysis \\
\hline Pavlo & Quantitative data analysis \\
\hline Rouane et al., 2013 & Multi relational data \\
\hline Li and Tsai, 2013 & Sentiments analysis \\
\hline Trabelsi et al., 2012 & Analyzing folksonomies \\
\hline 2012 & Probabilistic concepts \\
\hline Watmo & ERP analysis \\
\hline Yang et al., 2011b & Decision-making \\
\hline Zhao and Liu, 2011 & Complex systems \\
\hline Zhang et al., 2012 & Frequent concepts \\
\hline Tang et al., 2015 & Chemical structure \\
\hline Ontology engineering & Research goal \\
\hline Alqadah and Bhatnagar, 2012 & "Mining similar concepts \\
\hline Chen et & Merging domain ontology \\
\hline Dau, 2013 & Analyzing triple store \\
\hline Formica, 2012 & Semantic web search \\
\hline Formic & Similarity reasoning \\
\hline Fowler, 2013 & Ontology investigation \\
\hline Ilvovsky and Klimushki, 2013 & Duplicate ontology \\
\hline Junli et al., 2013 & Merging ontology \\
\hline Macko, 2013 & Friendly ontology \\
\hline De Maio et al., 2012b & E-learning \\
\hline De Maio et al., 2014 & Ontological structure \\
\hline Tadrat et al., 2012 & Case based reasoning \\
\hline Tho et al., 2006 & Fuzzy ontology \\
\hline
\end{tabular}

applications of data analysis. In this paper we have analyzed some of these extensions and augmentation of FCA with illustrative examples. The first categorized domain is granular based computing of formal concepts to describe their importance. Other domains discuss the mathematics behind FCA with a fuzzy setting, an interval-valued fuzzy setting, possibility theory, a rough setting, a triadic, factor and incomplete context to apply these extensions in the appropriate context for knowledge processing tasks. 
Table 22. Some important applications of FCA in text mining, information retrieval and linguistics.

\begin{tabular}{|c|c|}
\hline Text mining & Research goal \\
\hline Belohlavek and Macko, 2011 & Selecting \\
\hline Ferjani et al., 2012 & $\begin{array}{l}\text { Feature } \\
\text { extractions }\end{array}$ \\
\hline Formica, 2012 & Semantic web \\
\hline Galitsky et al., 2013 & $\begin{array}{l}\text { Finding patterns } \\
\text { on parse thickets }\end{array}$ \\
\hline Hamrouni et al., 2013 & $\begin{array}{l}\text { Finding some } \\
\text { frequent itemset }\end{array}$ \\
\hline Li and Guo, 2013 & $\begin{array}{l}\text { Investigating } \\
\text { formal query }\end{array}$ \\
\hline De Maio et al., 2014 & Text mining \\
\hline $\begin{array}{l}\text { Muangprathub et al., } 2013 \\
\text { Li and Tsai, } 2013\end{array}$ & $\begin{array}{c}\text { Classification } \\
\text { Text mining }\end{array}$ \\
\hline Information retrieval & Research goal \\
\hline Aswani Kumar et al., 2012 & Information retrieval \\
\hline Alqadah and Bhatnagar, 2012 & Similar concepts \\
\hline Bloch, 2011 & Bipolar information \\
\hline Eklund et al., 2012 & Similar concepts \\
\hline Chen et al., 2011 & Domain ontology \\
\hline Codocedo et al., 2012 & Finding cousins \\
\hline Neznanov and Kuznetsov, 2013 & FCART tool \\
\hline Poshyvanyk et al., 2012 & Concept location \\
\hline Priss, 2006 & $\begin{array}{l}\text { Application in } \\
\text { information sciences }\end{array}$ \\
\hline Senatore and Pasi, 2013 & Finding correlations \\
\hline Li and Tsai, 2013 & Opinion classification \\
\hline Zerarga and Djouadi, 2013 & Information retrieval \\
\hline Linguistics & Research goal \\
\hline $\begin{array}{l}\text { Alcalde } \text { et al., } 2011 \\
\text { Bloch, } 2011\end{array}$ & $\begin{array}{l}\text { Linguistic proposition } \\
\text { Linguistics } \\
\text { representation }\end{array}$ \\
\hline Chen et al., 2011 & Wordnet system \\
\hline Croitorua et al., 2012 & $\begin{array}{l}\text { Linguistics } \\
\text { analysis }\end{array}$ \\
\hline Muangprathub et al., 2013 & Classification \\
\hline Priss, 2005 & $\begin{array}{l}\text { Linguistics } \\
\text { application }\end{array}$ \\
\hline Yu et al., 2013 & Analyzing verbs \\
\hline
\end{tabular}

\section{Acknowledgment}

The first and the second author acknowledge the financial support from NBHM, DAE, Government of India, under the grant 2/48(11)/2010-R\&D II/10806. Further, the first and the third author acknowledge the financial support from the Mobile Cloud Computing research project funded by the Malaysian Ministry of Higher Education under the University of Malaya High Impact Research Grant UM.C/625/1/HIR/MOE/FCSIT/03. The authors also thank the anonymous reviewers for their useful suggestions and comments.
Table 23. Some important applications of FCA in security analysis, web services, social network analysis and software engineering.

\begin{tabular}{|c|c|}
\hline Security analysis & Research goal \\
\hline Aswani Kumar, 2013 & $\begin{array}{c}\text { Role based } \\
\text { access control }\end{array}$ \\
\hline Aufaure and Grand, 2013 & $\begin{array}{l}\text { Social network } \\
\text { analysis }\end{array}$ \\
\hline Cook and Coombs, 2004 & Military intelligence \\
\hline Du and Hai, 2013 & Mining web page \\
\hline Elzinga et al., 2010 & $\begin{array}{l}\text { Terrorist threat } \\
\text { assessment }\end{array}$ \\
\hline $\begin{array}{c}\text { Poelmans et al., } 2013 \mathrm{c} \\
\text { Priss, } 2011\end{array}$ & $\begin{array}{c}\text { Criminal trajectories } \\
\text { Unix system } \\
\text { monitoring }\end{array}$ \\
\hline Romanov et al., 2012 & Detect anomalies \\
\hline Web services & Research goal \\
\hline Qin et al., 2013 & Impact analysis \\
\hline De Maio et al., 2012a & E-learning \\
\hline Priss et al., 2013 & Software assessment \\
\hline Rouane et al., 2013 & $\begin{array}{l}\text { Mining from multi } \\
\text { relational data }\end{array}$ \\
\hline Watmough, 2014 & ERP analysis \\
\hline Tho et al., 2006 & Web retrieval \\
\hline Zhang et al., 2013a; 2013b & $\begin{array}{l}\text { Extracting data } \\
\text { from web database }\end{array}$ \\
\hline Social network analysis & Research goal \\
\hline Aufaure and Grand, 2013 & $\begin{array}{c}\text { FCA in social } \\
\text { network analysis }\end{array}$ \\
\hline Cook and Coombs, 2004 & $\begin{array}{c}\text { Network analysis } \\
\text { using FCA }\end{array}$ \\
\hline Elzinga et al., 2010 & $\begin{array}{c}\text { Terrorist threat } \\
\text { assessment by FCA }\end{array}$ \\
\hline Li et al., 2013c & $\begin{array}{c}\text { Call graph } \\
\text { for network }\end{array}$ \\
\hline Poelmans et al., 2013c & $\begin{array}{l}\text { Criminal trajectory } \\
\text { network analysis }\end{array}$ \\
\hline Wang et al., 2012 & $\begin{array}{c}\text { Wireless sensor } \\
\text { network }\end{array}$ \\
\hline Software engineering & Research goal \\
\hline$\overline{\text { Helen } \text { et al., } 2013}$ & $\begin{array}{c}\text { Energy saving } \\
\text { model using FCA }\end{array}$ \\
\hline Priss et al., 2012 & Learning process \\
\hline Rouane et al., 2013 & $\begin{array}{c}\text { Relational concept } \\
\text { analysis }\end{array}$ \\
\hline Sarnovsky et al., 2012 & $\begin{array}{l}\text { Distributed } \\
\text { S/W analysis }\end{array}$ \\
\hline
\end{tabular}

\section{References}

Akram, M. and Dudek, W.A. (2011). Interval valued fuzzy graphs, Computers Mathematics with Applications 61(2): 289-299.

Alcalde, C., Burusco, A., Fuentes-González, R. and Zubia, I. (2011). The use of linguistic variables and fuzzy propositions in the L-fuzzy concept theory, Computers and 
Table 24. Some important applications of FCA in bioinformatics, image processing and psychology.

\begin{tabular}{|c|c|}
\hline Bioinformatics & Research goal \\
\hline Amin et al., 2012 & Breast cancer \\
\hline Belohlavek et al., 2013b & $\begin{array}{l}\text { analysis using FCA } \\
\text { Study of taxonomy }\end{array}$ \\
\hline & behavior using FCA \\
\hline Gonzalez Calabozo et al., 2011 & Gene expression \\
\hline & data analysis \\
\hline Fan et al., 2013 & Analysis of Chinese \\
\hline & medicine using FCA \\
\hline Kaytoue et al., 2011b & Mining patterns in \\
\hline & Gene expression data \\
\hline Junli et al., 2013 & Merging geo-ontology \\
\hline Image processing & Research goal \\
\hline Atif et al., 2014 & Image processing \\
\hline Bloch, 2011 & $\begin{array}{l}\text { Morphology and its } \\
\text { link to FCA }\end{array}$ \\
\hline Croitorua et al., 2012 & Linguistics analysis \\
\hline De Maio et al., 2014 & Image processing \\
\hline & using fuzzy FCA \\
\hline Endres et al., 2012 & Analyzing the semantic \\
\hline Sawase et al., 2009 & Visualizino hure image \\
\hline & data using FCA \\
\hline Xu et al., 2012 & MapReduce framework \\
\hline & using FCA \\
\hline Psychology & Research goal \\
\hline Antoni et al., 2014 & Preference analysis \\
\hline Li and Tsai, 2013 & Opinion classification \\
\hline Poelmans, 2011 & Domestic violence \\
\hline Priss, 2006 & Information science \\
\hline Spoto et al., 2010 & Computerized psychological \\
\hline
\end{tabular}

Mathematics with Applications 62(8): 3111-3122.

Alcalde, C., Burusco, A. and Fuentes-González, R. (2012a). Analysis of certain L-fuzzy relational equations and the study of its solutions by means of the L-fuzzy concept theory, International Journal of Uncertainty, Fuzziness and Knowlege-Based Systems 20(1): 21-40.

Alcalde, C., Burusco, A. and Fuentes-González, R. (2012b). Composition of L-fuzzy contexts, Proceedings of the 10th ICFCA 2012, Leuven, Belgium, pp. 1-14 .

Alcalde, C., Burusco, A. and Fuentes-González, R. (2012c). The study of fuzzy context sequences, International Journal of Computational Intelligence Systems 6(3): 518-529.

Alcalde, C., Burusco, A. and Fuentes-González, R. (2015). The use of two relations in L-fuzzy contexts, Information Sciences 301: 1-14.

Alqadah, F. and Bhatnagar, R. (2012). Similarity measures in formal concept analysis, Annals of Mathematics and Artificial Intelligence 61(3): 245-256.

Amin, I.I., Kassim, S.K., Hassanien, A.E. and Hefny, H.A. (2012). Formal concept analysis for mining hypermethylated genes in breast cancer tumor subtypes, Proceedings of 12th ISDA, 2012, Kochi, India, pp. 764-769.

Annapurna, J. and Aswani Kumar, Ch. (2013). Exploring attribute with domain knowledge in formal concept analysis, Journal of Computing and Information Technology 21(2): 109-123.

Antoni, L., Krajci, S., Kridlo, O., Macek, B. and Piskova, L. (2014). On heterogeneous formal contexts, Fuzzy Sets and Systems 234: 22-33.

Aswani Kumar, Ch. (2011a). Reducing data dimensionality using random projections and fuzzy $K$-means clustering, International Journal of Intelligent Computing and Cybernetics 4(3): 353-365.

Aswani Kumar, Ch. (2011b). Knowledge discovery in data using formal concept analysis and random projections, International Journal of Applied Mathematics and Computer Science 21(4): 745-756, DOI: 10.2478/v10006-011-0059-1.

Aswani Kumar, Ch. (2012). Fuzzy clustering-based formal concept analysis for association rules mining, Applied Artificial Intelligence 26(3): 274-301.

Aswani Kumar, Ch. (2013). Designing role-based access control using formal concept analysis, Security and Communication Networks 6(3): 373-383.

Aswani Kumar, Ch., Radvansky, M., Fuentes-Gonzlez, R. and Annapurna, J. (2012). Analysis of a vector space model, latent semantic indexing and formal concept analysis for information retrieval, Cybernetics and Information Technologies 12(1): 34-48.

Aswani Kumar, Ch., Dias, S.M. and Vieira, N.J. (2015a). Knowledge reduction in formal contexts using non-negative matrix factorization, Mathematics and Computers in Simulation 109: 46-63.

Aswani Kumar, Ch., Ishwaryaa, M.S. and Loo, C.K. (2015b). Formal concept analysis approach to cognitive functionalities of bidirectional associative memory, Biologically Inspired Cognitive Architectures 22: 20-33, DOI:10.1016/j.bica.2015.04.003.

Aswani Kumar, Ch. and Singh, P.K. (2014). Knowledge representation using formal concept analysis: A study on concept generation, in B.K. Tripathy and D.P. Acharjya (Eds.), Global Trends in Knowledge Representation and Computational Intelligence, IGI Global Publishers, Hershey, PA, pp. 306-336.

Aswani Kumar, Ch. and Srinivas, S. (2010). Concept lattice reduction using fuzzy K-means clustering, Expert Systems with Application 37(3): 2696-2704.

Atif, J., Hudelot, C. and Bloch, I. (2014). Explanatory reasoning for image understanding using formal concept analysis and description logics, IEEE Transactions on Systems, Man, and Cybernetics A 44(4): 552-570.

Aufaure, M.A. and Grand, B.L. (2013). Advances in FCA-based applications for social networks analysis, International Journal of Conceptual Structures and Smart Applications 1(1): 73-89. 
Babin, M.A. and Kuznetsov, S.O. (2012). Approximating concept stability, in F. Domenach et al. (Eds.), Proceedings of the 10th International Conference, ICFCA 2012, Lecture Notes in Computer Science, Vol. 7278, Springer, Berlin/Heidelberg, pp. 7-15.

Babin, M.A. and Kuznetsov, S.O. (2013). Computing premises of minimal cover of functional dependencies is intractable, Discrete Applied Mathematics 161(6): 742-749.

Bartl, E., Rezankova, H. and Sobisek, L. (2011). Comparison of classical dimensionality reduction methods with novel approach based on formal concept analysis, in J.T. Yao et al. (Eds.), Rough Set and Knowledge Technology, Lecture Notes in Computer Science, Vol. 6954, Springer, Berlin/Heidelberg, pp. 26-35.

Bazhanov, K. and Obiedkov, S. (2014). Optimizations in computing the Duquenne-Guigues basis of implications, Annals of Mathematics and Artificial Intelligence 70(1): 5-24.

Belohlavek, R. (2012). Optimal decompositions of matrices with entries from residuated lattices, Annals of Mathematics and Artificial Intelligence 22(6): 1405-1425.

Belohlavek, R., Baets, B.D. and Konecny, J. (2014). Granularity of attributes in formal concept analysis, Information Sciences 260(5): 149-170.

Belohlavek, R., Glodeanu, C. and Vychodil, V. (2013a). Optimal factorization of three-way binary data using triadic concepts, Order 30(2): 437-454.

Belohlavek, R., Kostak, M. and Osicka, P. (2013b). Formal concept analysis with background knowledge: A case study in paleobiological taxonomy of belemnites, International Journal of General Systems 42(4): 426-440.

Belohlavek, R., and Macko, J. (2011). Selecting important concepts using weights, in P. Valtchev et al. (Eds.), Formal Concept Analysis, Lecture Notes in Computer Science, Vol. 6628, Springer, Berlin/Heidelberg, pp. 65-80.

Belohlavek, R., Sigmund, E. and Zacpal, J. (2011a). Evaluation of IPAQ questionnaires supported by formal concept analysis, Information Sciences 181(10): 1774-1786.

Belohlavek, R., Osicka, P. and Vychodil, V. (2011b). Factorizing three-way ordinal data using triadic formal concepts, in H. Christiansen et al. (Eds.), Flexible Query Answering Systems, Lecture Notes in Computer Science, Vol. 7022, Springer, Berlin/Heidelberg, pp. 400-411.

Belohlavek, R., and Osicka, P. (2012a). Triadic fuzzy Galois connections as ordinary connections, IEEE International Conference on Fuzzy Systems, Brisbane, Australia, pp. 1-6.

Belohlavek, R. and Osicka, P. (2012b). Triadic concept lattices of data with graded attributes, International Journal of General Systems 41(2): 93-108.

Belohlavek, R., and Trnecka, M. (2013). Basic level in formal concept analysis: Interesting concepts and psychological ramifications, Proceedings of the 23rd International Joint Conference on Artificial Intelligence, Beijing, China, pp. 1233-1239.
Belohlavek, R. and Vychodil, V. (2005). Fuzzy attribute logic: Entailment and non-redundant basis, 11th International Fuzzy Systems Association World Congress, Tsinghua, China, pp. 622-627.

Belohlavek, R. and Vychodil, V. (2012). Formal concept analysis and linguistic hedges, International Journal of General Systems 41(5): 503-532.

Biao, X., Ruairi, de F., Eric, R. and Micheal, F. (2012). Distributed formal concept analysis algorithms based on an iterative map reduce framework, in $\mathrm{F}$. Domenach et al. (Eds.), Formal Concept Analysis, Lecture Notes in Computer Science, Vol. 7278, Springer, Berlin/Heidelberg, pp. 292-308.

Bloch, I. (2011). Lattices of fuzzy sets and bipolar fuzzy sets and mathematical morphology, Information Sciences 181(10): 2002-2015.

Borgwardt, S. and Penaloza, R. (2014). Consistency reasoning in lattice-based fuzzy description logics, International Journal of Approximate Reasoning 55(9): 1917-1938.

Bouaud, J., Messai, N., Laouenan, C., Mentre, F. and Seroussi, B. (2013). Elicitating patient patterns of physician non-compliance with breast cancer guidelines using formal concept analysis, Studies in Health Technology and Informatics 180: 471-481.

Butka, P., Pocs, J. and Pocsova, J. (2012). Use of concept lattices for data tables with different types of attributes, Journal of Information and Organizational Sciences 36(1): 1-12.

Chen, J., Lia, J., Lin, Y., Lin, G. and Ma, Z. (2015). Relations of reduction between covering generalized rough sets and concept lattices, Information Sciences 304: 16-27.

Chen, R.C., Bau, C.T. and Yeh, C.J. (2011). Merging domain ontologies based on the WordNet system and fuzzy formal concept analysis techniques, Applied Soft Computing 11(2): 1908-1923.

Ciobanu, G. and Vaideanu, C. (2014). Similarity relations in fuzzy attribute-oriented concept lattices, Fuzzy Sets and Systems 275: 88-109.

Codocedo, V., Taramasco, C. and Astudillo, H. (2011). Cheating to achieve formal concept analysis over a large formal context, Proceedings of the 11th International Conference on Concept Lattices and Their Applications, Kosice, Slovakia, pp. 349-362.

Codocedo, V., Lykourentzou, I. and Napoli, A. (2012). Semantic querying of data guided by formal concept analysis, Formal Concept Analysis for Artificial Intelligence, Nancy, France.

Cook, T.M. and Coombs, M. (2004). Using formal concept analysis (FCA) to model and represent counterdeception analytic tasks, Proceedings of the 13th International Conference on Behavior Representation in Modeling and Simulation, Arlington, VA, USA, pp. 7-8.

Croitorua, M., Orenb, N., Milesc, S. and Luckc, M. (2012). Graphical norms via conceptual graphs, Knowledge-Based Systems 29: 31-43. 
Dau, F. (2013). Towards scalingless generation of formal contexts from an ontology in a triple stores, International Journal of Conceptual Structures and Smart Applications 1(1): 18-38.

Davey, B.A. and Priestley, H.A. (2002). Introduction to Lattices and Order, Cambridge University Press, Cambridge.

De Maio, C., Fenza, G., Loia, V. and Senatore, S. (2012a). Hierarchical web resources retrieval by exploiting fuzzy formal concept analysis, Information Processing and Management 48(3): 399-418.

De Maio, C., Fenza, G., Gaeta, M., Loia, V., Orciuoli, F. and Senatore, S. (2012b). RSS-based e-learning recommendations exploiting fuzzy FCA for knowledge modeling, Applied Soft Computing 12(1): 113-124.

De Maio, C., Fenza, G., Gallo, M., Loia, V. and Senatore, S. (2014). Formal and relational concept analysis for fuzzy-based automatic semantic annotation, Applied Intelligence 40(1): 153-174.

Denniston, J.T., Melton, A. and Rodabaugh, S.E. (2013). Formal concept analysis and lattice-valued Chu systems, Fuzzy Sets and Systems 216: 52-90.

Dias, S.M., Zarate, L.E. and Vieira, N.J. (2013). Extracting reducible knowledge from ANN with JBOS and FCANN approaches, Expert Systems with Applications 40(8): 3087-3095.

Dias, S.M., and Vieira, N.J. (2013). Applying the JBOS reduction method for relevant knowledge extraction, $E x$ pert Systems with Applications 40(5): 1880-1887.

Dias, S.M. and Vieira, N.J. (2015). Concept lattices reduction: Definition, analysis and classification, Expert Systems with Applications 42(20): 7084-7097, DOI: 10.1016/j.eswa.2015.04.044

Distel, F. (2012). Adapting fuzzy formal concept analysis for fuzzy description logics, Proceedings of CLA, Fuengirola, Spain, pp. 163-174.

Djouadi, Y. (2011). Extended Galois derivation operators for information retrieval based on fuzzy formal concept lattice, in S. Benferhat et al. (Eds.), Scalable Uncertainty Management, Lecture Notes in Computer Science, Vol. 6929, Springer, Berlin/Heidelberg, pp. 346-358.

Djouadi, Y. and Prade, H. (2009). Interval-valued fuzzy formal concept analysis, in J. Rauch et al. (Eds.), Foundations of Intelligent System, Lecture Notes in Artificial Intelligence, Vol. 5722, Springer, Berlin/Heidelberg, pp. 592-601.

Doerfel, S., Jaschke, R. and Stumme, G. (2012). Publication analysis of the formal concept analysis community, in F. Domenach et al. (Eds.), Formal Concept Analysis, Lecture Notes in Computer Science, Vol. 7278, Springer, Berlin/Heidelberg, pp. 77-95.

Du, Y. and Hai, Y. (2013). Semantic ranking of web pages based on formal concept analysis, Journal of Systems and Software 86(1): 187-197.

Dubois, D. and Prade, H. (2012). Possibility theory and formal concept analysis: Characterizing independent sub-contexts, Fuzzy Sets and Systems 196: 4-16.
Endres D., Adam, R., Giese. M.A. and Noppeney, U. (2012). Understanding the semantic structure of human fMRI brain recordings with formal concept analysis, in F. Domenach et al. (Eds.), Formal Concept Analysis, Lecture Notes in Computer Science, Vol. 7278, Springer, Berlin/Heidelberg, pp. 96-111.

Eklund, P., Ducrou, J. and Dau, F. (2012). Concept similarity and related categories in information retrieval using formal concept analysis, International Journal of General Systems 41(8): 826-846.

Elzinga, P., Viaene, S., Poelmans, J., Dedene, G. and Morsing, S. (2010). Terrorist threat assessment with formal concept analysis, Proceedings of the 2010 IEEE International Conference on Intelligence and Security Informatics, Vancouver, BC, Canada, pp. 77-82.

Fan, F., Hong, W., Song, J., Jing, J. and Ji, S. (2013). A visualization method for Chinese medicine knowledge discovery based on formal concept analysis, ICIC Express Letters 4(3): 801-808.

Ferjani, F., Elloumi, S., Jaoua, A., Ben Yahia, S., Ismail, S. and Ravan, S. (2012). Formal context coverage based on isolated labels: An efficient solution for text feature extraction, Information Sciences 188: 198-214.

Formica, A. (2012). Semantic web search based on rough sets and fuzzy formal concept analysis, Knowledge-Based Systems 26(3): 40-47.

Formica, A. (2013). Similarity reasoning for the semantic web based on fuzzy concept lattices: An informal approach, Information Systems Frontiers 15(3): 511-520.

Fowler, M. (2013). The taxonomy of a Japanese stroll garden: An ontological investigation using formal concept analysis, Axiomathes 13(1): 43-59.

Fu, H. and Mephu Nguifo, E. (2004). A parallel algorithm to generate formal concepts for large data, in P. Eklund (Ed.), Concept Lattices, Lecture Notes in Computer Science, Vol. 2961, Springer, Berlin/Heidelberg, pp. 394-401.

Ganter, B. and Glodeanu, C.V. (2012). Ordinal factor analysis, in F. Domenach et al. (Eds.), Formal Concept Analysis, Lecture Notes in Computer Science, Vol. 7278, Springer, Berlin/Heidelberg, pp. 128-139.

Ganter, B. and Meschke, C. (2011). A formal concept analysis approach to rough data tables, in H. Sakai et al. (Eds.), Rough Sets, Fuzzy Sets, Data Mining and Granular Computing, Lecture Notes in Computer Science, Vol. 6600, Springer, Berlin/Heidelberg, pp. 37-61.

Ganter, B. and Wille, R. (1999). Formal Concept Analysis: Mathematical Foundation, Springer-Verlag, Berlin.

Galitsky, B.A., Ilvovsky, D., Strok, F. and Kuznetsov, S.O. (2013). Improving text retrieval efficiency with pattern structures on parse thickets, Proceedings of FCAIR 2013, Moscow, Russia, pp. 6-21.

Glodeanu, C.V. (2011). Factorization with hierarchical classes analysis and formal concept analysis, in P. Valtchev et al. (Eds.), Formal Concept Analysis, Lecture Notes in Computer Science, Vol. 6628, Springer, Berlin/Heidelberg, pp. 107-118. 
Glodeanu, C.V. (2012). Attribute dependency in fuzzy setting, Proceedings of CLA 2012, Fuengirola, Spain, pp. 127-138.

Glodeanu, C.V. and Ganter, B. (2012). Applications of ordinal factor analysis, in P. Cellier et al. (Eds.), Formal Concept Analysis, Lecture Notes in Computer Science, Vol. 7880, Springer, Berlin/Heidelberg pp. 109-124.

Gonzalez Calabozo, J.M., Pelaez-Moreno, C. and Valverde-Albacete, F.J. (2011). Gene expression array exploration using $\mathrm{K}$-formal concept analysis, in $\mathrm{P}$. Valtchev and R. Jäschke (Eds.), Proceedings of the 9th International Conference ICFCA 2011, Lecture Notes in Computer Science, Vol. 6628, Springer, Berlin/Heidelberg, pp. 119-134.

Hamrouni, T., Ben Yahia, S. and Mephu Nguifo, E. (2013). Looking for a structural characterization of the sparseness measure of (frequent closed) itemset contexts, Information Sciences 222: 343-361.

Helen, Z., David, J. and Zhao, X.J. (2013). Construction of new energy-saving building materials based on formal concept analysis methods, Advanced Materials Research 738: $133-136$.

Helmi, B.H., Rahmani, A.T. and Pelikan, M. (2014). A factor graph based genetic algorithm, International Journal of Applied Mathematics and Computer Science 24(3): 621-633, DOI: 10.2478/amcs-2014-0045.

Ignatov, D.I., Kuznetsov, S.O., Magizov, R.A. and Zhukov, L.E. (2011). From triconcepts to triclusters, in S.O. Kuznetsov et al. (Eds.) Rough Sets, Fuzzy Sets, Data Mining and Granular Computing, Lecture Notes in Computer Science, Vol. 6743, Springer, Berlin/Heidelberg, pp. 257-264.

Ignatov, D.I., Gnatyshak, D.V., Kuznetsov, S.O. and Mirkin, B.G. (2015). Triadic formal concept analysis and triclustering: Searching for optimal patterns, Machine Learning 101(1): 271-302, DOI:10.1007/s10994-015-5487-y.

Ilvovsky, D. and Klimushkin, M. (2013). FCA-based search for duplicate objects in ontologies, Proceedings of FCAIR, Moscow, Russia, pp. 36-46.

Iordache, O. (2011). Modeling multi-level systems, Understanding Complex Systems 70: 143-163.

Junli, L., Zongyi, H. and Qiaoli, Z. (2013). An entropy-based weighted concept lattice for merging multi-source geo-ontologies, Entropy 15(6): 2303-2318.

Kaiser, T.B. and Schmidt, S.E. (2013). A macroscopic approach to FCA and its various fuzzifications, in F. Domenach et al. (Eds.), Formal Concept Analysis, Lecture Notes in Computer Science, Vol. 7278, Springer, Berlin/Heidelberg, pp. 140-147.

Kang, X., Li, D., Wang, S. and Qu, K. (2012a). Formal concept analysis based on fuzzy granularity base for different granulations, Fuzzy Sets and Systems 203: 33-48.

Kang, X., Li, D., Wang, S. and Qu, K. (2012b). Rough set model based on formal concept analysis, Information Sciences 222: 611-625.
Kaytoue, M., Kuznetsov, S.O., Napoli, A. and Polaillon, G. (2011a). Symbolic data analysis and formal concept analysis, XVIIIeme Rencontres de la Societe Francophone de Classification-SFC, Orléans, France, pp. 1-4.

Kaytoue, M., Kuznetsov, S.O., Napoli, A. and Duplessis, S. (2011b). Mining gene expression data with pattern structures in formal concept analysis, Information Sciences 181: 1989-2001.

Krajca, P, Outrata, J. and Vychodil, V. (2008). Parallel recursive algorithm for FCA, Proceedings of CLA, Olomouc, Czech Republic, pp. 71-82.

Krajca, P., Outrata, J. and Vychodil, V. (2012). Concept lattices of incomplete data, in F. Domenach et al. (Eds.), Formal Concept Analysis, Lecture Notes in Computer Science, Vol. 7278, Springer, Berlin/Heidelberg, pp. 180-194.

Korei, A. (2013). Applying formal concept analysis in machine-part grouping problems, Proceedings of the 11th International Symposium on Applied Machine Intelligence and Informatics 2013, Herl'any, Slovakia, pp. 197-200.

Kuznetsov, S.O. (2013). Fitting pattern structures to knowledge discovery in big data, in P. Cellier et al. (Eds.), Formal Concept Analysis, Lecture Notes in Computer Science, Vol. 7880, Springer, Berlin/Heidelberg, pp. 254-266.

Kuznetsov, S.O. and Obiedkov, S.A. (2002). Comparing performance of algorithms for generating concept lattices, Journal of Experimental and Theoretical Artificial Intelligence 14(2-3): 189-216.

Kuznetsov, S.O. and Poelmans, J. (2013). Knowledge representation and processing with formal concept analysis, Wiley Interdisciplinary Reviews: Data Mining and Knowledge Discovery 3(3): 200-215.

Langdon, W.B., Yoo, S. and Harma, M. (2011). Formal concept analysis on graphics hardware, Proceedings of CLA, Nancy, France, pp. 413-416.

Lei, Y. and Tian, J. (2012). Concepts with negative-values and corresponding concept lattices, Proceedings of the 9th International Conference on Fuzzy Systems and Knowledge Discovery, Sichuan, China, pp. 1005-1008.

Li, J., Changlin, M. and Yuejin, L. (2011a). A heuristic knowledge-reduction method for decision formal contexts, Computers and Mathematics with Applications 61(4): 1096-1106.

Li, J., Changlin, M. and Yuejin, L. (2011b). Knowledge reduction in decision formal contexts, Knowledge-Based Systems 24(5): 709-715.

Li, J., Mei, C. and Lv, Y. (2012a). Knowledge reduction in real decision formal contexts, Information Sciences 189(5): 191-207.

Li, J., Mei, C. and Lv, Y. (2012b). Knowledge reduction in formal decision contexts based on an order-preserving mapping, International Journal of General Systems 41(5): 143-161.

Li, J., Mei, C. and Lv, Y. (2013a). Incomplete decision contexts: Approximate concept construction, rule acquisition and knowledge reduction, International Journal of Approximate Reasoning 54(1): 149-165. 
Li, J., Mei, C., Aswani Kumar, Ch. and Lv, Y. (2013b). On rule acquisition in decision formal contexts, International Journal of Machine Learning and Cybernetics 4(6): 721-731.

Li, B., Suna, X. and Leungc, H. (2013c). Combining concept lattice with call graph for impact analysis, Advances in Engineering Software 53: 41-43.

Li, J., Mei, C., Xu, W. and Qian, Y. (2015). Concept learning via granular computing: A cognitive viewpoint, Information Sciences 298: 447-467.

Li, M.Z. and Guo, L. (2013). Formal query systems on contexts and a representation of algebraic lattices, Information Sciences 239: 72-74.

Li, M.Z. and Mi, J.S. (2013). The strong direct product of formal contexts, Information Sciences 226: 47-67.

Li, S.T. and Tsai, F.C. (2013). A fuzzy conceptualization model for text mining with application in opinion polarity classification, Knowledge-Based Systems 39: 23-33.

Ma, J.M. and Zhang, W.X. (2013). Axiomatic characterizations of dual concept lattices, International Journal of Approximate Reasoning 54(5): 690-697.

Macko, J. (2013). User-friendly fuzzy FCA, in P. Cellier et al. (Eds.), Proceedings of the 11th International Conference ICFCA 2013, Lecture Notes in Computer Science, Vol. 7880, Springer, Berlin/Heidelberg, pp. 156-171.

Mariano, F.L., Asuncion, G.P. and Mari Carmen, S.F. (2013). Methodological guidelines for reusing general ontologies, Data and Knowledge Engineering 86: 242-275.

Martin, T.P., Abd Rahim, N.H. and Majidian, A. (2013). A general approach to the measurement of change in fuzzy concept lattices, Soft Computing 17(12): 2223-2234.

Martin, T. and Majidian, A. (2013). Finding fuzzy concepts for creative knowledge discovery, International Journal of Intelligent Systems 28(1): 93-114.

Massanet, S., Mayor, G., Mesiar, R. and Torrens, J. (2013). On fuzzy implications: An axiomatic approach, International Journal of Approximate Reasoning 54(9): 1471-1482.

Medina, J. (2012a). Relating attribute reduction in formal, object-oriented and property-oriented concept lattices, Computers and Mathematics with Applications 64(6): 1992-2002.

Medina, J. (2012b). Multi-adjoint property-oriented and object-oriented concept lattices, Information Sciences 190: 95-2006.

Medina, J. and Ojeda-Aciego, M. (2012). On multi-adjoint concept lattices based on heterogeneous conjunctors, Fuzzy Sets and Systems 208: 95-110.

Missaoui, R. and Kwuida, L. (2011). Mining triadic association rules from ternary relations, in P. Valtchev and R. Jäschke (Eds.), Proceedings of the 9th International Conference ICFCA 2011, Lecture Notes in Computer Science, Vol. 6628, Springer, Berlin/Heidelberg, pp. 204-218.

Muangprathub, J., Boonjing, V. and Pattaraintakorn, P. (2013). A new case-based classification using incremental concept lattice knowledge, Data and Knowledge Engineering 83: 39-53.
Muszyński, M. and Osowski, S. (2013). Data mining methods for gene selection on the basis of gene expression arrays, International Journal of Applied Mathematics and Computer Science 24(3): 657-668, DOI: 10.2478/amcs-2014-0048.

Neznanov, A. and Kuznetsov, S.O. (2013). Information retrieval and knowledge discovery with FCART, in S.O. Kuznetsov et al. (Eds.), Proceedings of FCAIR, Vol. 977, Moscow, pp. 74-82.

Nguyen, T.T., Hui, S.C and Chang, K. (2011). A lattice-based approach for mathematical search using formal concept analysis, Expert Systems with Applications 39(5): 5820-5828.

Nguyen, V.A. and Yamamoto, A. (2012). Learning from graph data by putting graphs on the lattice, Expert Systems with Applications 39(12): 11172-11182.

Obiedkov, S. (2012). Modeling preferences over attribute sets in formal concept analysis, in F. Domenach et al. (Eds.), Proceedings of the 10th International Conference ICFCA 2012, Lecture Notes in Computer Science, Vol. 7278, Springer, Berlin/Heidelberg, pp. 227-243.

Outrata, J. and Vychodil, V. (2012). Fast algorithm for computing fixpoints of Galois connections induced by object-attribute relational data, Information Sciences 185(1): 114-127.

Pavlovic, D. (2012). Quantitative concept analysis, in F. Domenach et al. (Eds.), Formal Concept Analysis, Lecture Notes in Computer Science, Vol. 7278, Springer, Berlin/Heidelberg, pp. 260-277.

Pedrycz, W. (2013). Granular Computing Analysis and Design of Intelligent Systems, CRC Press, Boca Raton, FL.

Pei, Z., Ruan, D., Meng, D. and Liu, Z. (2013). Formal concept analysis based on the topology for attributes of a formal context, Information Sciences 236: 66-82.

Pocs, J. (2012). On possible generalization of fuzzy concept lattices using dually isomorphic retracts, Information Sciences 210: 89-98.

Poelmans, J. (2011). Formally analyzing the concepts of domestic violence, Expert Systems with Applications 38(4): 3116-3130.

Poelmans, J., Ignatov, D.I., Kuznetsov, S.O. and Dedene, G. (2013a). Formal concept analysis in knowledge processing: A survey on models and techniques, Expert Systems with Applications 40(16): 6601-6623.

Poelmans, J., Kuznetsov, S.O., Ignatov, D.I. and Dedene, G. (2013b). Formal concept analysis in knowledge processing: A survey on applications, Expert Systems with Applications 40(16): 6538-6560.

Poelmans, J., Elzinga, P. and Dedene, G. (2013c). Retrieval of criminal trajectories with an FCA-based approach, in O. Kuznetsov et al. (Eds.), Proceedings of FCAIR, Vol. 977, Moscow, pp. 83-94.

Poelmans, J., Ignatov, D.I., Kuznetsov, S.O. and Dedene, G. (2014). Fuzzy and rough formal concept analysis: A survey, International Journal of General Systems 43(2): 105-134. 
Poshyvanyk, D., Gethers, M. and Marcus, A. (2012). Concept location using formal concept analysis and information retrieval, ACM Transactions on Software Engineering and Methodology 21(4), Article No. 23, DOI:10.1145/2377656.2377660.

Priss, U. (2005). Linguistic applications of formal concept analysis, in B. Ganter et al. (Eds.), Formal Concept Analysis: Foundations and Applications, Lecture Notes in Computer Science, Vol. 3626, Springer, Berlin/Heidelberg, pp. 149-160.

Priss, U. (2006). Formal concept analysis in information science, Annual Review of Information Science and Technology 40(1): 521-543.

Priss, U. (2011). Unix systems monitoring with FCA, in S. Andrews et al. (Eds.), Conceptual Structures for Discovering Knowledge, Lecture Notes in Artificial Intelligence, Vol. 6828, Springer, Berlin/Heidelberg, pp. 243-256.

Priss, U. (2012). Concept lattices and median networks, Proceedings of CLA, Derby, UK, pp. 351-354.

Priss, U., Peter, R. and Jensen, N. (2012). Using FCA for modelling conceptual difficulties in learning processes, in S. Andrews et al. (Eds.), Conceptual Structures for Discovering Knowledge, Vol. 6828, Springer, Berlin/Heidelberg, pp. 161-173.

Priss, U., Jensen, N. and Rod, O. (2013). Using conceptual structures in the design of computer-based assessment software, in H.D. Pfeiffer et al. (Eds.), Conceptual Structures for Discovering Knowledge, Lecture Notes in Artificial Intelligence, Vol. 7735, Springer, Berlin/ Heidelberg, pp. 193-209.

Qin, X., Liu, K. and Tang, S. (2013). Fuzzy FCA-based web service discovery, Journal of Information and Computational Science 9(17): 5477-5484.

Rainer, B. and Ganapati, P. (2011). Formal concept analysis: Ranking and prioritization for multi-indicator systems, Environmental and Ecological Statistics 5: 117-133.

Radvansky, M., Sklenar, V. and Snasel, V. (2013). Evaluation of stream data by formal concept analysis, in M. Pechenizkiy and M. Wojciechowski (Eds.), New Trends in Databases and Information Systems, Advances in Intelligent Systems and Computing, Vol. 185, Springer, Berlin/Heidelberg pp. 131-140.

Romanov, V., Poluektova, A. and Sergienko, O. (2012). Adaptive EIS with business rules discovered by formal concept analysis, in C. Moller and S. Chaudhry (Eds.), Reconceptualizing Enterprise Information Systems, Lecture Notes in Business Information Processing, Vol. 105, Springer, Berlin/Heidelberg, pp. 105-117.

Rouane, H.M., Huchard, M., Napoli, A. and Valtchev, P. (2013). Relational concept analysis: Mining concept lattices from multi-relational data, Annals of Mathematics and Artificial Intelligence 67(1): 81-108.

Ruairi, de F. (2013). Formal concept analysis via atomic priming, in P. Cellier et al. (Eds.), Formal Concept Analysis, Lecture Notes and Computer Science, Vol. 7880, Springer, Berlin/Heidelberg, pp. 92-108.
Saquer, J. and Deogun, J.S. (2001). Concept approximations based on rough sets and similarity measures, International Journal of Applied Mathematics and Computer Science 11(3): 655-674.

Sarmah, A.K., Hazarika, S.M. and Sinha, S.K. (2015). Formal concept analysis: Current trends and directions, Artificial Intelligence Review 44: 47-86, DOI:10.1007/s10462-013-9404-0.

Sarnovsky, M., Butka, P. and Pocsova, J. (2012). Cloud computing as a platform for distributed fuzzy FCA approach in data analysis, Proceedings of the IEEE 16th International Conference on Intelligent Engineering Systems, Lisbon, Portugal, pp. 291-296.

Sawase, K., Nobuhara, H. and Bede, B. (2009). Visualizing huge image databases by formal concept analysis, Studies in Computational Intelligence 182: 291-296.

Sebastien, N., Fabien, P., Lotfi, L. and Rosine, C. (2013) The agree concept lattice for multidimensional database analysis, in P. Valtchev and R. Jäschke (Eds.), Formal Concept Analysis, Lecture Notes and Computer Science, Vol 6628, Springer, Berlin/Heidelberg, pp. 219-234.

Senatore, S. and Pasi, G. (2013). Lattice navigation for collaborative filtering by means of (fuzzy) formal concept analysis, Proceedings of the 28th Annual ACM Symposium on Applied Computing, Coimbra, Portugal, pp. 920-926.

Shao, M.W., Leung, Y. and Wu, W.Z. (2014). Rule acquisition and complexity reduction in formal decision contexts, International Journal of Approximate Reasoning 55(1): 259-274.

Simiński, K. (2012). Neuro-rough-fuzzy approach for regression modelling from missing data, International Journal of Applied Mathematics and Computer Science 22(2): 461-476, DOI: $10.2478 / \mathrm{v} 10006-012-0035-4$.

Singh, P.K. and Aswani Kumar, Ch. (2012a). Interval-valued fuzzy graph representation of concept lattice, Proceedings of the 12th ISDA, Kochi, India, pp. 604-609.

Singh, P.K. and Aswani Kumar, Ch. (2012b). A method for decomposition of fuzzy formal context, Procedia Engineering 38: 1852-1857.

Singh, P.K. and Aswani Kumar, Ch. (2014). Bipolar fuzzy graph representation of concept lattice, Information Sciences 288: $437-448$.

Singh, P.K. and Aswani Kumar, Ch. (2015a). A note on computing the crisp order context of a fuzzy formal context for knowledge reduction, Journal of Information Processing Systems 11(2): 184-204.

Singh, P.K. and Aswani Kumar, Ch. (2015b). Analysis of composed contexts through projection, International Journal of Data Analysis Techniques and Strategies, (in press).

Singh, P.K., Aswani Kumar, Ch. and Li, J. (2015a). Concepts reduction in formal concept analysis with fuzzy setting using Shannon entropy, International Journal of Machine Learning and Cybernetics, DOI: 10.1007/s13042-014-0313-6. 
Singh, P.K., Aswani Kumar, Ch. and Jinhai, Li (2015b). Knowledge representation using interval-valued fuzzy formal concept lattice, Soft Computing, DOI: 10.1007/s00500-015-1600-1.

Singh, P.K. and Gani, A. (2015). Fuzzy concept lattice reduction using Shannon entropy and Huffman coding, Journal of Applied Non-Classical Logics 25(2): 101-119, DOI: 10.1080/11663081.2015.1039857.

Slezak, D. (2012). Rough sets and FCA-Scalability challenges, in F. Domenach et al. (Eds.), Formal Concept Analysis, Lecture Notes and Computer Science, Vol. 7378, Springer, Berlin/Heidelberg, p. 6.

Spoto, A., Stefanutti, L. and Vidotto, G. (2010). Knowledge space theory, formal concept analysis, and computerized psychological assessment, Behavior Research Methods 42(1): 342-350.

Tadrat, J., Boonjing, V. and Pattaraintakorn, P. (2012). A new similarity measure in formal concept analysis for case-based reasoning, Expert Systems with Applications 39(1): 967-972.

Tang, P., Huia, S.C. and Fong, C.M.A. (2015). A lattice-based approach for chemical structural retrieval, Engineering Applications of Artificial Intelligence 39: 215-222.

Tho, Q.T., Hui, S.C. and Cao, T.H. (2006). Automatic fuzzy ontology generation for semantic web, IEEE Transactions on Knowledge and Data Engineering 18(6): 842-856.

Trabelsi, C., Jelassi, N. and Yahia, S.B. (2012). Scalable mining of frequent tri-concepts from Folksonomies, in P.-N. Tan et al. (Eds.), Advances in Knowledge Discovery and Data Mining, Lecture Notes and Computer Science, Vol. 7302, Springer, Berlin/Heidelberg, pp. 231-242.

Vityaev, E.E., Demin, A.V. and Ponomaryov, D.K. (2012). Probabilistic generalization of formal concepts, Programming and Computer Software 38(5): 219-230.

Wang, T.Z and Xu, H.S. (2011). Constructing domain ontology based on fuzzy set and concept lattice, Applied Mechanics and Materials 63-64: 715-718.

Wang, X. and Li, G. (2012). A similarity measure model based on rough concept lattice, in Y. Wu (Ed.), Software Engineering and Knowledge Engineering: Theory and Practice, Advances in Intelligent and Soft Computing, Vol. 114, Springer, Berlin/Heidelberg, pp. 99-103.

Wang, Y., Zhang, J. and Xu, H. (2012). The design of data collection methods in wireless sensor networks based on formal concept analysis, in D. Jin and S. Lin (Eds.), $A d$ vances in Computer Science and Information Engineering, Advances in Intelligent and Soft Computing, Vol. 169, Springer, Berlin/Heidelberg, pp. 33-38.

Watmough, M. (2014). Discovering the hidden semantics in enterprise resource planning data through formal concept analysis, Studies in Computational Intelligence 495: 291-314.

Wille, R. (1982). Restructuring lattice theory: An approach based on hierarchies of concepts, in I. Rival (Ed.), Ordered Sets, Reidel, Dordrecht/Boston, MA, pp. 445-470.
Wu, L., Qiua, D. and Mi, J.S. (2012). Automata theory based on complete residuated lattice-valued logic: Turing machines, Fuzzy Sets and Systems 208(12): 43-66.

Wu, W.Z., Leung, Y. and Mi, J.S. (2009). Granular computing and knowledge reduction in formal contexts, IEEE Transactions on Knowledge and Data Engineering 21(10): 1461-1474.

Xu, B., Frein, R.D., Robson, E. and Foghlu, M.O. (2012). Distributed formal concept analysis algorithms based on an iterative MapReduce framework, in F. Domenach et al. (Eds.), Formal Concept Analysis, Lecture Notes in Computer Science, Vol. 7278, Springer, Berlin/Heidelberg, pp. 292-308.

$\mathrm{Xu}, \mathrm{W}$. and Li, W. (2015). Granular computing approach to two-way learning based on formal concept analysis in fuzzy datasets, IEEE Transactions on Cybernetics 46(2): 366-379, DOI: 10.1109/TCYB.2014.2361772.

Yan, H., Zou, C., Liu, J. and Wang, Z. (2015). Formal concept analysis and concept lattice: Perspectives and challenges, International Journal of Autonomous and Adaptive Communications Systems 8(1): 81-96.

Yang, H. (2011). Formal concept analysis based on rough set theory and a construction algorithm of rough concept lattice, in H. Deng et al. (Eds.), Emerging Research in Artificial Intelligence and Computational Intelligence, Communications in Computer and Information Science, Vol. 237, Springer, Berlin/Heidelberg, pp. 239-244.

Yang, H.Z., Yee, L. and Shao, M.W. (2011a). Rule acquisition and attribute reduction in real decision formal contexts, Soft Computing 15(6): 1115-1128.

Yang, Y.P., Shieh, H.M., Tzeng, G.Z., Yen, L. and Shao, M.W. (2011b). Combined rough sets with flow graph and formal concept analysis for business aviation decision-making, Journal of Intelligent Information Systems 36(3): 347-366.

Yao, Y. (2004). A comparative study of formal concept analysis and rough set theory in data analysis, in $\mathrm{S}$. Tsumoto et al. (Eds.), Rough Sets and Current Trends in Computing, Lecture Notes in Artificial Intelligence, Vol. 3066, Springer, Berlin/Heidelberg, pp. 59-66.

Yao, Y., Mi, J., Li, Z. and Xie, B. (2012). The construction of fuzzy concept lattices based on $(\theta, \sigma)$-fuzzy rough approximation operators, Fundamenta Informaticae 111(1): $33-45$

Yu, J., Hong, W., Li, S., Zhang, T. and Shao, M.W. (2013). A new approach of word sense disambiguation and knowledge discovery of English modal verbs by formal concept analysis, International Journal of Innovative Computing, Information and Control 9(3): 1189-1200.

Zerarga, L. and Djouadi, Y. (2013). Interval-valued fuzzy extension of formal concept analysis for information retrieval, in T. Huang et al. (Eds.), Neural Information Processing, Lecture Notes in Computer Science, Vol. 7663, Springer, Berlin/Heidelberg, pp. 608-615.

Zhai, Y., Li, D. and Qu, K. (2012). Probability fuzzy attribute implications for interval-valued fuzzy set, International Journal of Database Theory and Application 5(4): 95-108. 
Zhai, Y., Li, D. and Qu, K. (2013). Fuzzy decision implications, Knowledge-Based Systems 37: 230-236.

Zhang, S., Guo, P., Zhang, J., Wang, X. and Pedrycz, W. (2012). A completeness analysis of frequent weighted concept lattices and their algebraic properties, Data and Knowledge Engineering 81-82: 104-117.

Zhang, L., Zhang, H., Shen, X. and Yin, L. (2013a). A bottom-up algorithm of vertical assembling concept lattices, International Journal of Data Mining and Bioinformatics 7(3): 229-244.

Zhang, Z., Du, J. and Yin, L. (2013b). Formal concept analysis approach for data extraction from a limited deep web database, Journal of Intelligent Information Systems 41(2): 1-24.

Zhao, J. and Liu, L. (2011). Construction of concept granule based on rough set and representation of knowledge-based complex system, Knowledge-Based Systems 24(6): 809-815.

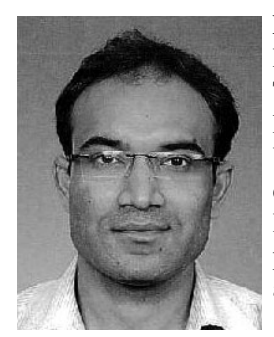

Prem Kumar Singh is a postdoc fellow at the Faculty of Computer Science and Information Technology, University of Malaya, Malaysia. He holds a Ph.D. degree in computer science from VIT University, India. His research interests include formal concept analysis and graph theory. $\mathrm{He}$ has published more than 15 refereed research papers so far in various international conferences and journals.

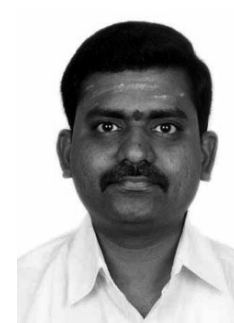

Cherukuri Aswani Kumar is a professor at the Network and Information Security Division, School of Information Technology and Engineering, VIT University, Vellore, India. He holds a Ph.D. degree in computer science from VIT University. His current research interests are formal concept analysis and machine intelligence. $\mathrm{He}$ has published 70 refereed research papers so far in various conferences and journals. $\mathrm{He}$ is a senior member of the ACM and is associated with other professional bodies including the ISC, CSI, ISTE.
Abdullah Gani is a professor at the Faculty of Computer Science and Information Technology, University of Malaya, Malaysia. He holds bachelor and master degrees from the University of Hull, UK, and a Ph.D. from the University of Sheffield, UK. His research interests include machine learning and mobile cloud computing. He has published more than 100 research papers in various conferences and journals.

Received: 25 April 2014

Revised: 11 December 2014

Re-revised: 10 April 2015

Accepted: 26 May 2015 